\title{
Papilionoidea de la Sierra de Huautla, Morelos y Puebla, México (Insecta: Lepidoptera)
}

\author{
Mercedes Luna-Reyes ${ }^{1}$, Jorge Llorente-Bousquets ${ }^{2 *} \&$ Armando Luis-Martínez ${ }^{2}$ \\ 1. Museo de Zoología, Facultad de Estudios Superiores Zaragoza, Av. Guelatao No. 66. Col. Ejército de Oriente. \\ Iztapalapa. México D.F. 09230; mmluna@puma2.zaragoza.unam.mx, alm@hp.fciencias.unam.mx \\ 2. Museo de Zoología, Facultad de Ciencias, UNAM. Apartado Postal 70-399, México D.F. 04510. *Responsable de la \\ publicación; jlb@ hp.fciencias.unam.mx
}

Recibido 04-VIII-2007. Corregido 30-VI-2008. Aceptado 31-VII-2008.

\begin{abstract}
Papilionoidea from Sierra de Huautla, Morelos and Puebla, México (Insecta: Lepidoptera). The Cuenca del Balsas region has significant biodiversity and endemicity of its herpetofauna, avifauna and vascular plants. Despite this, our knowledge of the Papilionoidea of the region is poor. We analyzed the local and temporal distribution of Papilionoidea at 24 localities in the states of Morelos and Puebla. The study sites are situated between 900 and 1300 m. a. s. 1., and are composed of dry tropical forest (dtf). We recorded 8790 individuals of 83 genera and 142 species of Papilionoidea (sensu Kristensen, 1975), over 79 days of field work, with 2-4 days at each of the 24 localities. Twenty five species were newly recorded for the state of Puebla. Our data render Morelos and Puebla among the seven richest Mexican states, in terms of Papilionoidea diversity. Our results show that the Sierra de Huautla has the lowest diversity, but the highest standard abundance, compared to other Mexican regions with similar vegetation. Patterns of diversity and seasonal abundance are atypical, in that individuals of many species are unusually abundant during the wet months. Rev. Biol. Trop. 56 (4): 1677 1716. Epub 2008 December 12.
\end{abstract}

Key words: Cuenca del Balsas, dry tropical forest, phenology, richness, tropical forest.

En los últimos años se ha aplicado el término megadiverso para aquellos países que tienen representados en su superficie valores extraordinarios de la biodiversidad mundial; este reducido grupo solo incluye 12 países, México ocupa el séptimo lugar, por su gran riqueza biológica y por su alta proporción de endemismos (Mittermeier y Goettsch 1992, CONABIO 2002). Rzedowski (1992) estimó que en el territorio mexicano existen 22,800 especies de plantas vasculares, que representan alrededor del $10 \%$ de las registradas a nivel mundial (Flores y Gerez 1994). En cuanto a la fauna, el análisis de la riqueza muestra que en México habita el 10\% de los vertebrados del mundo, aunque en los anfibios está representado alrededor del 7\% faltan muchos por descubrir y describir. Los valores de endemismo también resultan altos, oscilando entre $10 \%$ en aves y 55.7\% en herpetofauna (Espinosa 1993, Flores 1993, Navarro y Benítez 1993, Arita y León 1993, Fa y Morales 1993).

Los insectos incluyen alrededor del 60-65\% de la biota descrita (Morón y Valenzuela 1993, Llorente et al. 1996, Luis et al. 2000). El orden Lepidoptera se considera uno de los grupos hiperdiversos (Martín-Piera y Lobo 2000), con 146,000 especies, agrupadas en 27 superfamilias; una de las cuales es Papilionoidea que representa el $13.1 \%$ especies descritas de lepidópteros en todo el mundo (Llorente et al. 1996, Lamas 2000). De acuerdo con los resultados por Luis et al. (2003b), del total de 1016 especies de papilionoideos (sensu Kristensen 1975) reconocidas para México, el $8.66 \%$ es endémico. Además de la importancia 
que tiene por su riqueza, Papilionoidea ha sido ampliamente utilizado como modelo en trabajos sobre análisis de la biodiversidad, en impacto ambiental y bioconservación, así como en estudios sistemáticos, biogeográficos, genéticos, etológicos y ecológicos; muchas de sus especies han sido consideradas por los especialistas como indicadoras del estado de los hábitats y su riqueza (Beccaloni y Gaston 1995, Llorente et al. 1996, Brown K. 1997).

Una de las áreas bióticas poco estudiadas, que a la vez coincide con perturbaciones extensas, corresponde al tipo de vegetación de selvas caducifolias (Trejo y Dirzo 2000). Esta comunidad vegetal predomina en la cuenca del Balsas, en el estado de Morelos y sur del estado de Puebla. La sierra de Huautla forma parte de la Cuenca en estos estados, región donde habita gran diversificación biológica, concentrándose en ella parte de las especies endémicas de fanerógamas (Flores y Gerez 1994) y valores altos de riqueza y especies endémicas para la herpetofauna (Flores 1993) y aves mexicanas (Escalante et al. 1993).

Este estudio tiene el propósito de contribuir al conocimiento de la diversidad de los Papilionoidea de la cuenca oriental del Balsas $\mathrm{y}$, en particular, de la sierra de Huautla y áreas adyacentes en Morelos y Puebla. Además del reconocimiento de la riqueza del área, se describe la distribución regional y la estacionalidad de la comunidad.

Antecedentes: De acuerdo con la información registrada en la Comisión Nacional para el Conocimiento y Uso de la Biodiversidad (CONABIO), existen más de 500 mil registros de ejemplares de mariposas recolectadas en México. A pesar de esto, el mapa de las localidades de recolecta del Atlas de Mariposas de México, desarrollado actualmente por los investigadores del Museo de Zoología de la Facultad de Ciencias de la UNAM (Llorente et al. 1997, Luis et al. 2003b), claramente indica que la lepidopterofauna de las selvas bajas caducifolias de México está poco estudiada y que, en particular, en la sierra de Huautla solo se habían registrado cinco especies distribuidas en tres localidades. Por ello es que resulta necesario el desarrollo de estudios que permitan conocer la composición faunística de las comunidades de mariposas asociadas con este tipo de vegetación.

Un estudio equivalente al nuestro en áreas próximas corresponde al publicado por De la Maza (1975); otros desarrollados por este autor se efectuaron con fines biogeográficos en áreas de menor altitud, que también incluyen otros tipos de vegetación (De la Maza et al. 1995a,b).

Descripción del Área de Estudio: La sierra de Huautla en conjunto con la sierra de Taxco, actualmente se considera como una de la Regiones Terrestres Prioritarias para la conservación en México (RTP-120). Esta región denominada como sierras de Taxco-Huautla, se ubica entre las coordenadas $18^{\circ} 18^{\prime} 32^{\prime \prime}$ $18^{\circ} 52^{\prime} 21^{\prime \prime} \mathrm{N}, 98^{\circ} 48^{\prime} 49^{\prime \prime}-100^{\circ} 09^{\prime} 00^{\prime}$ W, e incluye parte de los estados de México, Guerrero, Morelos y Puebla, ocupando una superficie de $2959 \mathrm{~km}^{2}$ (CONABIO 2000).

Geología y Edafología: La sierra de Huautla fundamentalmente está constituida por rocas ígneas extrusivas del Terciario, sobre las que se han desarrollado asociaciones de suelos someros (10 a $50 \mathrm{~cm}$ de profundidad) de tipo feozem háplico más regosoles y vertisoles.

Fisiografía: La sierra de Huautla está en un límite de la provincia fisiográfica del Eje Neovolcánico y presenta características geológicas heterogéneas debido a su proximidad con la Sierra Madre del Sur, con la que comparte varios rasgos. Se ubica dentro de la Subprovincia de las sierras abruptas del sur de Puebla e incluye áreas de los estados de Puebla y Morelos. Esta sierra es adyacente a la cuenca alta del Balsas.

Hidrografía: El área está drenada por diferentes ríos afluentes del río Balsas, como el Amacuzac en el extremo occidental y el Tepalcingo, el Nexapa y el Huehuetlán hacia la parte oriental. Todos ellos nutridos por multitud de arroyos. 
Clima y vegetación: En la sierra de TaxcoHuautla se presentan cinco subtipos de clima de acuerdo con la clasificación de Köppen modificada por García (1981). La mayor parte corresponde a $(\mathrm{A}) \mathrm{C}\left(\mathrm{w}_{2}\right)$, que es un clima semicálido y subhúmedo, con lluvias en verano; después y casi en la misma proporción $\mathrm{Aw}_{\mathrm{o}} \mathrm{y}$ $\mathrm{Aw}_{1}$ que son climas cálidos-subhúmedos con lluvias en verano; $(\mathrm{A}) \mathrm{C}\left(\mathrm{w}_{1}\right)$, clima semicálido $\mathrm{y}$ subhúmedo, con lluvias en verano y $\mathrm{C}\left(\mathrm{w}_{2}\right) \mathrm{x}$, clima templado al que le corresponde la menor parte (CONABIO 2000).

En el área de estudio predomina el clima de tipo cálido subhúmedo con régimen de lluvias de verano, con poca oscilación térmica y marcha de temperatura tipo ganges $-A w_{0}(w)$ $(i$ ') $g$ - donde se desarrolla la selva baja caducifolia que se presenta con intensidades de perturbación diferentes, en asociación con porciones transformadas en pastizales inducidos y áreas de cultivo (INEGI 1981). Aunque existen áreas cubiertas por bosques de encino, pino, pino-encino, mesófilo y zacatonal alpino, y otras en las que se realizan actividades agrícolas y pecuarias, para la sierra Taxco-Huautla la vegetación predominante (41\%) es la selva baja caducifolia (CONABIO 2000).

\section{MATERIAL Y MÉTODOS}

Recolección de ejemplares: De febrero de 1997 hasta julio de 2000, se efectuaron 79 visitas diarias al área de estudio, repartidas a lo largo de 25 meses con un promedio de dos a cuatro días por mes, muestreando así en 24 localidades de selva baja caducifolia ubicadas en un intervalo altitudinal entre los 900 y 1300 $\mathrm{m}$, en los estados de Morelos y Puebla. En el Cuadro 1 se presenta la relación de los sitios elegidos, el municipio y estado al que pertenecen, así como los datos de la georreferenciación y altitud obtenidos con un GPS marca Garmin modelo12 XL.

La recolecta de individuos se llevó a cabo mediante el uso de redes entomológicas aéreas. En cada sitio se efectuó un recorrido a lo largo de un transecto de $2 \mathrm{~km}$, explorando entre la vegetación, en las laderas, paredes y oquedades de las elevaciones, en el lecho de arroyos o ríos, o sobre el suelo húmedo de las orillas de charcos, arroyos o ríos, o sobre su lecho seco, en veredas y caminos y en cualquier microhábitat donde se observaran mariposas, siguiendo las técnicas recomendadas por Howe (1975), Pollard (1977) y Clench (1979). El tiempo de permanencia en cada localidad fue de cuatro horas en el período comprendido de las 0800 a las 1900 aproximadamente. Los ejemplares fueron capturados al vuelo, sobre el sustrato alimentario o sobre arena húmeda mediante la red aérea indicada; las recolectas se efectuaron por al menos dos personas, aunque en algunos sitios participaron seis con diversas habilidades.

Cada mariposa capturada fue sacrificada y colocada de manera individual en una bolsa de papel "glassine", en la que se anotaron los datos de localidad, fecha, hora y nombre del colector.

\section{Procesamiento del material entomológi-} co: Se preparó una muestra de ejemplares de cada localidad y especie, de acuerdo con las técnicas convencionales propuestas por Howe (1975) para el montaje de ejemplares. Así mismo, el material fue rotulado incluyendo los datos nomenclaturales (especie o subespecie, según el caso), de recolecta (localidad, fecha, coordenadas geográficas, altitud, hora, tipo de vegetación y nombre del colector) y el número de catálogo y el de recolecta que identifica a cada ejemplar. Finalmente, el material fue incorporado a la colección lepidopterológica del Museo de Zoología de la F.E.S. Zaragoza, UNAM.

Determinación taxonómica: Todos los ejemplares fueron mantenidos en cajas con cristales de paradiclorobenceno durante tres semanas. Después se procedió a su determinación taxonómica, para lo cual se consultaron obras especializadas e ilustradas como las de Ehrlich y Ehrlich (1961), Emmel (1975), Pyle y Knopf (1981), Scott (1986), De la Maza (1987), DeVries (1987), Smart (1989), Llorente et al. (1997) y Luis et al. (2003a), así como 
CUADRO 1

Localidades estudiadas en la Sierra de Huautla

TABLE 1

Studied localities at Sierra de Huautla

\begin{tabular}{ccl}
$\#$ & Clave & Localidad \\
1 & TL & Tlancualpicán \\
2 & CH & Chiautla \\
3 & TE & Teotlaco \\
4 & HU & Huehuetlán \\
5 & AL & Barranca El Almagre \\
6 & LN & Los Linderos \\
7 & AX & Axochiapan \\
8 & JO & Jolalpan \\
9 & TC & San Miguel Tecolacio \\
10 & AT & Atlacahualoya \\
11 & CU & Río Cuautla \\
12 & SA & Los Sauces \\
13 & IG & Ixtlilco El Grande \\
14 & LM & El Limón \\
15 & AF & Agua Fría \\
16 & TP & El Tepehuaje \\
17 & IC & Ixtlilco El Chico \\
18 & CM & Chinameca \\
19 & AC & Santa Cruz Achichipico \\
20 & PT & Pitzotlán \\
21 & VI & Viborillas \\
22 & PM & Puente Marquéz \\
23 & XU & Santa María Xuchapa \\
\hline
\end{tabular}

\begin{tabular}{|c|c|c|c|c|}
\hline Municipio & Estado & Latitud & Longitud & $\begin{array}{l}\text { Altitud } \\
\text { (m snm }\end{array}$ \\
\hline Chiahutla & Puebla & $18^{\circ} 25^{\prime}$ & $98^{\circ} 45^{\prime}$ & 900 \\
\hline Chiahutla & Puebla & $18^{\circ} 20^{\prime}$ & $98^{\circ} 35^{\prime}$ & 1000 \\
\hline Teotlalco & Puebla & $18^{\circ} 22^{\prime}$ & $98^{\circ} 49^{\prime}$ & 900 \\
\hline Huehuetlán & Puebla & $18^{\circ} 21^{\prime}$ & $98^{\circ} 41^{\prime}$ & 1100 \\
\hline Chiahutla & Puebla & $18^{\circ} 24^{\prime} 38^{\prime \prime}$ & $98^{\circ} 41^{\prime} 10^{\prime \prime}$ & 900 \\
\hline Chiahutla & Puebla & $18^{\circ} 17^{\prime} 35^{\prime \prime}$ & $98^{\circ} 42^{\prime} 40^{\prime \prime}$ & 1200 \\
\hline Axochiapán & Morelos & $18^{\circ} 304^{\prime} 8^{\prime \prime}$ & $98^{\circ} 45^{\prime} 10^{\prime \prime}$ & 1050 \\
\hline Jolalpán & Puebla & $18^{\circ} 21^{\prime} 42^{\prime \prime}$ & $98^{\circ} 49^{\prime} 8^{\prime \prime}$ & 900 \\
\hline Chietla & Puebla & $18^{\circ} 26^{\prime} 28^{\prime \prime}$ & $98^{\circ} 40^{\prime} 2^{\prime \prime}$ & 1220 \\
\hline Axochiapán & Morelos & $18^{\circ} 33^{\prime} 20^{\prime \prime}$ & $98^{\circ} 44^{\prime} 13^{\prime \prime}$ & 1000 \\
\hline Tlaquiltenango & Morelos & $18^{\circ} 36^{\prime}$ & $98^{\circ} 7^{\prime}$ & 900 \\
\hline Tepalcingo & Morelos & $18^{\circ} 35^{\prime} 12.2^{\prime \prime}$ & $98^{\circ} 56^{\prime} 46.8^{\prime \prime}$ & 1216 \\
\hline Tepalcingo & Morelos & $18^{\circ} 32^{\prime} 17^{\prime \prime}$ & $98^{\circ} 51^{\prime} 6^{\prime \prime}$ & 1100 \\
\hline Tepalcingo & Morelos & $18^{\circ} 30^{\prime} 50.5^{\prime \prime}$ & $98^{\circ} 57^{\prime} 17.8^{\prime \prime}$ & 1213 \\
\hline Tepalcingo & Morelos & $18^{\circ} 34^{\prime} 45.3^{\prime \prime}$ & $98^{\circ} 49^{\prime} 37.5^{\prime \prime}$ & 1009 \\
\hline Tepalcingo & Morelos & $18^{\circ} 34^{\prime} 50.5^{\prime \prime}$ & $98^{\circ} 58^{\prime} 50.4^{\prime \prime}$ & 1280 \\
\hline Tepalcingo & Morelos & $18^{\circ} 33^{\prime} 54^{\prime \prime}$ & $98^{\circ} 52^{\prime} 18^{\prime \prime}$ & 1100 \\
\hline Ayala & Morelos & $18^{\circ} 37^{\prime} 28^{\prime \prime}$ & $98^{\circ} 57^{\prime} 4^{\prime \prime}$ & 1300 \\
\hline Axochiapán & Morelos & $18^{\circ} 29^{\prime}$ & $98^{\circ} 49^{\prime}$ & 1000 \\
\hline Tepalcingo & Morelos & $18^{\circ} 34^{\prime}$ & $98^{\circ} 54^{\prime}$ & 1200 \\
\hline Chietla & Puebla & $18^{\circ} 29^{\prime} 7.6^{\prime \prime}$ & $98^{\circ} 30^{\prime} 15.9^{\prime \prime}$ & 1174 \\
\hline Tehuitzingo & Puebla & $18^{\circ} 23^{\prime} 14.5^{\prime \prime}$ & $98^{\circ} 18^{\prime} 40.2^{\prime \prime}$ & 1000 \\
\hline $\begin{array}{l}\text { Izucar de } \\
\text { Matamoros }\end{array}$ & Puebla & $18^{\circ} 32^{\prime} 17.5^{\prime \prime}$ & $98^{\circ} 26^{\prime} 45.4^{\prime \prime}$ & 1250 \\
\hline Tepexco & Puebla & $18^{\circ} 38^{\prime} 42.4^{\prime \prime}$ & $98^{\circ} 40^{\prime} 30.7^{\prime \prime}$ & 1240 \\
\hline
\end{tabular}

la colección lepidopterológica del Museo de Zoología de la F.E.S. Zaragoza (MZFZ) y la colección del Museo de Zoología de la Facultad de Ciencias (MZFC), ambas de la UNAM.

Registro de ejemplares: Con los datos registrados se elaboró un catálogo escrito que después fue transferido a una base de datos electrónica en el modelo BióticA (versión 3.1), a partir de la cual se procesaron los registros con los cuales se elaboraron cuadros y figuras utilizados en el análisis de distribución regional y temporal de la riqueza, así como la abundancia de los papilionoideos del área estudiada.

Lista de especies: Se integró la lista de especies de papilionoideos que fueron registrados en la totalidad del área de estudio. Este 
inventario se presenta siguiendo la nomenclatura y el orden filogenético propuesto por Kristensen (1975) para la superfamilia Papilionoidea, y a Tyler et al. (1994) para Papilionidae; para las demás familias (Pieridae, Nymphalidae y Lycaenidae) el orden propuesto por Scott (1985), Luis et al. (1991, 2003a), Vargas et al. (1992, 1999) y Llorente et al. (1997).

Esfuerzo de captura: Para cada sitio se elaboraron curvas de acumulación de especies donde se ilustran los valores observados de la riqueza específica y los estimados mediante el índice de $\mathrm{Chao}_{1}$ (Colwell y Coddington 1994). Los registros de especies por sitio se anexaron a una matriz de incidencia (presencia-ausencia) de tipo $r \times c$, donde los renglones son especies y las columnas son localidades de recolecta. También se trazó la curva de acumulación de las especies registradas y se aplicó el índice de $\mathrm{ChaO}_{2}$ (Colwell y Coddington 1994, LeónCortés et al. 1998), indicador que se utiliza en estudios que consideran pocos muestreos o que se realizan en períodos cortos y donde existe gran cantidad de especies raras; con él se puede estimar la riqueza teórica de una región requiriendo únicamente los datos de presenciaausencia de las especies (Feria 1997).

Con propósitos de comparación también se aplicaron los métodos sugeridos por Soberón y Llorente (1993) e instrumentados por DíazFrancés y Soberón (2005).

Riqueza y abundancia: Se analizó la riqueza y la abundancia total, así como su distribución espacial y temporal en el área de estudio. Para ello la lista de especies fue contrastada con la obtenida en estudios realizados por González (1996) en Puebla, y Luna-Reyes (2007) y Luna-Reyes et al. (en prep.) en Morelos, en los que se llevó a cabo una revisión exhaustiva de la colección del MZFZ y del MZFC con su megabase de datos MARIPOSA y de la literatura especializada sobre las especies citadas para estas áreas. También se consultaron los trabajos de De la Maza (1975), Lara (1999), Valencia (1999) y Vences (2004), así como las obras : Catálogo Sistemático y Zoogeográfico de los Lepidópteros Mexicanos (Hoffmann 1940), Mariposas de México (Beutelspacher 1984), Mariposas Mexicanas (De la Maza 1987), Papilionidae y Pieridae de México: Distribución geográfica e Ilustración (Llorente et al. 1997) y Nymphalidae de México I (Danaine, Apaturinae, Biblidinae y Heliconiinae): Distribución geográfica e Ilustración (Luis et al. 2003a).

La riqueza total del área de estudio se comparó con la encontrada en trabajos metodológicamente similares a éste, en los que se reconoció la diversidad de Papilionoidea de regiones amplias en las que se incluyeron varias localidades, como la sierra de Juárez, Oaxaca (Luis et al. 1991), la sierra de Atoyac de Álvarez, Guerrero (Vargas et al. 1992) y la sierra de Manantlán, Colima y Jalisco (Vargas et al. 1999). También se establecieron comparaciones con trabajos efectuados en áreas con vegetación tropical (selva baja caducifolia o subcaducifolia) ubicadas en Morelos o en otros estados del país, como Pedernales (Balcázar 1988) y Chorros del Varal (Arteaga 1991) en Michoacán, Zenzontla y Ahuacapán en Jalisco (Vargas et al. 1999) y Cañón de Lobos en Morelos (Luna-Reyes 2007).

Puesto que el esfuerzo de captura (horas/ día/persona) efectuado fue diferente en las distintas localidades de la sierra de Huautla, en el análisis de abundancia se consideraron los datos de la abundancia estandarizada (abundancia/esfuerzo de captura). Se siguió el mismo tratamiento para los datos de los sitios con los que se comparó este trabajo y en los que también se registró con detalle la abundancia y el esfuerzo de captura empleado: Agua Dulce y Platanarillos en Colima, Ahuacapán, La Calera, Los Mazos y Zenzontla en Jalisco (Vargas et al. 1999), y Cañón de Lobos en Morelos (LunaReyes 2007).

Abundancia por especie: Se contabilizó el número de especímenes directamente y por categorías de abundancia. Las especies fueron ordenadas de acuerdo con su abundancia en seis categorías siguiendo la escala geométrica 
en agrupamientos de tamaño por cuatro: MR (Muy Rara: especies con un ejemplar), R (Rara: dos a cinco ejemplares), E (Escasa: seis a 21), F (Frecuente: 22 a 85), C (Común: 86 a 331) y MC (Muy Común: especies con 332 ejemplares o más), de acuerdo con las propuestas de Lamas (1984), Krebs (1985) y Luis y Llorente (1990).

Fenología: Todos los datos de riqueza y abundancia del área de estudio fueron agrupados por mes y, como en los análisis anteriores, la abundancia fue estandarizada. Estos resultados fueron comparados con los trabajos de Arteaga (1991), Vargas et al. $(1992,1999) \mathrm{y}$ Luna-Reyes (2007).

\section{RESULTADOS}

Lista sistemática y riqueza: Se registraron 142 especies, 83 géneros y cuatro familias de Papilionoidea, con base en la determinación taxonómica de los 8790 especímenes recolectados en 24 localidades de la sierra de Huautla.

\section{PAPILIONOIDEA DE LA SIERRA DE HUAUTLA}

\section{PAPILIONIDAE}

\section{Baroniinae}

Baronia

1. B. brevicornis brevicornis Salvin, 1893

\section{Papilioninae}

\section{Protographium}

2. P. epidaus fenochionis (Salvin \& Godman, 1868)

\section{Battus}

3. B. philenor philenor (Linnaeus, 1771)

4. B. polydamas polydamas (Linnaeus, 1758)

\section{Parides}

5. P. erithalion trichopus (Rothschild \& Jordan, 1906)

6. P. montezuma (Westwood, 1842)
7. P. photinus (Doubleday, 1844)

\section{Heraclides}

8. H. cresphontes (Cramer, 1777)

9. H. ornythion ornythion (Boisduval, 1836)

10. H. rogeri pharnaces (Doubleday, 1846)

11. H. thoas autocles (Rothschild \& Jordan, 1906)

\section{Papilio}

12. P. polyxenes asterius Stoll, 1782

Pterourus

13. P. multicaudata multicaudata (W. F. Kirby, 1884)

\section{PIERIDAE}

\section{Coliadinae}

\section{Zerene}

14. Z. cesonia cesonia (Stoll, 1791)

Anteos

15. A. maerula (Fabricius, 1775)

Phoebis

16. P. agarithe agarithe (Boisduval, 1836)

17. P. argante ssp. n.

18. P. philea philea (Linnaeus, 1763)

19. P. sennae marcellina (Cramer, 1777)

\section{Aphrissa}

20. A. statira statira (Cramer, 1777)

Abaeis

21. A. nicippe (Cramer, 1779)

Pyrisitia

22. $\quad$ P. dina westwoodi (Boisduval, 1836)

23. P. lisa centralis (Herrich-Schäffer, 1865)

24. P. nise nelphe (R. Felder, 1869)

25. P. proterpia (Fabricius, 1775)

\section{Eurema}

26. E. arbela boisduvaliana (C. Felder \& R. Felder, 1865)

27. E. daira sidonia (R. Felder, 1869)

28. E. mexicana mexicana (Boisduval, 1836) 
29. E. salome jamapa (Reakirt, 1866)

Nathalis

30. N. iole Boisduval, 1836

Kricogonia

31. K. lyside (Godart, 1819)

\section{Pierinae}

Hesperocharis

32. H. costaricensis pasion (Reakirt, [1867])

Glutophrissa

33. G. drusilla tenuis (Lamas, 1981)

Leptophobia

34. L. aripa elodia (Boisduval, 1836)

Ascia

35. A. monuste monuste (Linnaeus, 1764)

Ganyra

36. G. josephina josepha (Salvin \& Godman, 1868 )

NYMPHALIDAE

Libytheinae

Libytheana

37. L. carinenta mexicana Michener, 1943

\section{Danainae}

Danaus

38. D. eresimus montezuma Talbot, 1943

39. D. gilippus thersippus (W. H. Bates, 1863)

40. D. plexippus plexippus (Linnaeus, 1758)

\section{Morphiinae}

Morpho

41. M. polyphemus polyphemus Westwood, 1851

\section{Satyrinae}

Cissia

42. C. pompilia (C.Felder \& R. Felder, 1867)
43. C. similis (Butler, 1867)

44. C. themis (Butler, 1867)

Euptychia

45. E. fetna Butler, 1870

Hermeuptychia

46. H. hermes (Fabricius, 1775)

Megisto

47. M. rubricata rubricata (W. H. Edwards, 1871)

Pindis

48. P. squamistriga R. Felder, 1869

Taygetis

49. T. weymeri Draudt, 1912

\section{Charaxinae}

Anaea

50. A. troglodyta aidea (Guérin-Ménéville, [1844])

\section{Apaturinae}

Asterocampa

51. A. idyja argus (H. W. Bates, 1864)

Doxocopa

52. D. laure laure (Drury, 1773)

\section{Nymphalinae}

Vanessa

53. V. annabella (Field, 1971)

\section{Smyrna}

54. S. blomfildia datis Frühstorfer, 1908

Anartia

55. A. amathea fatima Fabricius, 1793

56. A. jatrophae luteipicta Frühstorfer, 1907

Junonia

57. J. coenia Hübner, [1822]

58. J. evarete nigrosuffusa Barnes \& McDunnough, 1916 
Siproeta

59. S. stelenes biplagiata (Frühstorfer, 1907)

Anthanassa

60. A. nebulosa alexon (Godman \& Salvin, 1889)

61. A. ptolyca amator (A. Hall, 1929)

62. A. texana texana (W. H. Edwards, 1863)

Chlosyne

63. C. hippodrome hippodrome (Geyer, 1837)

64. C. janais janais (Drury, 1782)

65. C. lacinia lacinia (Geyer, 1837)

66. C. rosita riobalsensis Bauer, 1961

67. C. ehrenbergii (Geyer, [1833])

Microtia

68. M. elva elva H. W. Bates, 1864

Phyciodes

69. P. mylitta thebais Godman y Salvin, 1878

70. P. pallescens (R. Felder, 1869)

71. P. pulchella pulchella (Boisduval, 1852)

Tegosa

72. T. frisia tulcis (H.W. Bates, 1864)

Texola

73. T. anomalus coracara (Dyar, 1912)

74. T. elada elada (Hewitson, 1868)

Mestra

75. M. dorcas amymone (Ménétriés, 1857)

Eunica

76. E. monima (Stoll, 1782

Myscelia

77. M. cyananthe cyananthe C. \& R. Felder, 1867

Hamadryas

78. H. amphinome mexicana (Lucas, 1853)
79. H. atlantis lelaps (Godman \& Salvin, 1883)

80. H. februa ferentina (Godart, [1824])

81. H. glauconome glauconome (W. $\mathrm{H}$. Bates, 1864)

82. H. guatemalena marmarice (Frühstorfer, 1916)

\section{Bolboneura}

83. B. sylphis beatrix R. G. Maza, 1985

Cyclogramma

84. C. bacchis (Doubleday, 1849)

Adelpha

85. A. iphicleola iphicleola (H.W. Bates, 1864)

Marpesia

86. M. chiron marius (Cramer, 1779)

87. M. petreus ssp. n.

\section{Heliconiinae}

Euptoieta

88. E. claudia daunius (Herbst, 1798)

89. E. hegesia meridiania Stichel, 1938

Agraulis

90. A. vanillae incarnata (Riley, 1926)

Dione

91. D. juno huascuma (Reakirt, 1866)

92. D. moneta poeyii Butler, 1873

Dryas

93. D. iulia moderata (Riley, 1926)

Heliconius

94. H. charithonia vazquezae W. P.

Comstock y F. M. Brown, 1950

LYCAENIDAE

Theclinae

Cyanophrys

95. C. goodsoni Clench, 1946

Rekoa

96. R. palegon (Cramer, 1780)

97. R. zebina (Hewitson, 1869) 
Arawacus

98. A. jada (Hewitson, 1867)

Chlorostrymon

99. C. simaethis (Drury, 1770)

100. C. telea (Hewitson, 1868)

Allosmaitia

101. A. strophius (Godart, [1824])

Calycopis

102. C. isobeon (Butler \& H. Druce, 1872)

Electrostrymon

103. E. sangala (Hewitson, 1868)

Strymon

104. S. rufofusca (Hewitson, 1877)

105. S. yojoa (Reakirt, [1867])

106. S. cestri (Reakirt, [1867])

107. S. albata (C. Felder \& R. Felder, 1865)

108. S. bebrycia (Hewitson, 1868)

109. S. istapa (Reakirt, [1867])

110. S. bazochii (Godart, [1824])

\section{Ministrymon}

111. M. clytie (W. H. Edwards, 1877)

112. M. azia (Hewitson, 1873)

\section{Panthiades}

113. P. bitias (Cramer, 1777)

114. P. bathildis (C. Felder \& R. Felder, 1865)

115. "Thecla” sp.

\section{Polyommatinae}

Leptotes

116. L. cassius cassidula (Boisduval, 1870)

117. L. marina (Reakirt, 1868)

Zizula

118. Z. cyna (W. H. Edwards, 1881)

Everes

119. E. comyntas (Godart, [1824])

Hemiargus

120. H. hanno antibubastus Hübner, [1808]
Echinargus

121. E. isola (Reakirt, [1867])

\section{Riodininae}

Calephelis

122. C. nemesis nemesis (W. H. Edwards, 1871)

123. C. perditalis perditalis Barnes \& McDunnough, 1918

124. C. rawsoni McAlpine, 1939

125. Calephelis sp.

Caria

126. C. stillaticia Dyar, 1912

\section{Baeotis}

127. B. zonata zonata R. Felder, 1869

Lasaia

128. L. sessilis Schaus, 1890

129. L. maria maria Clench, 1972

Melanis

130. M. cephise acroleuca R. Felder, 1869

Emesis

131. E. mandana furor Butler \& H. Druce, 1872

132. E. vulpina Godman y Salvin, 1886

133. E. poeas Godman, 1901

134. E. tenedia C. Felder \& R. Felder, 1861

135. E. lupina lupina Godman \& Salvin, 1886

136. E. zela cleis (W. H. Edwards, 1882)

137. E. emesia (Hewitson, 1867)

Apodemia

138. A. palmeri australis Austin, 1988

139. A. walkeri Godman y Salvin, 1886

Thisbe

140. T. lycorias lycorias (Hewitson, [1853])

Juditha

141. J. molpe molpe (Hübner, [1808])

Theope

142. T. eupolis Schaus, 1890 
Veinticinco especies son registros nuevos para Puebla (ver Apéndice I), de tal forma que con este trabajo, el número total de especies para Puebla es de 432. Por el contrario, para Morelos todas las especies que integran esta lista se encuentran entre las 355 del catálogo de Papilionoidea que se ha desarrollado desde hace más de 15 años para este estado (LunaReyes 2007, Luna-Reyes et al., en prep.).

De acuerdo con Luis et al. (2003b), las entidades en las que se ha detectado la mayor riqueza de Papilionoidea en nuestro país son: Chiapas (824 especies), Oaxaca (771), Veracruz (676), Guerrero (477), Jalisco (399), en esta jerarquización los estados de Puebla (432) y Morelos (355) ocupan el quinto y séptimo lugar, respectivamente (Cuadro 2).

En la sierra de Huautla se presentan 18 de los taxones endémicos a México (Luis et al. 2000, 2003b): Baronia b. brevicornis, $P$. epidaus fenochionis, P. erithalion trichopus, E. fetna, T. weymeri, A. nebulosa alexon, A. ptolyca amator, C. rosita riobalsensis, C. ehrenbergii, $P$. pallescens, T. anomalus coracara, T. e. elada, $H$. atlantis lelaps, $H$. guatemalena marmarice, B. sylphis beatrix y $M$. cephise acroleuca, E. poeas y A. palmeri australis (Apéndice I).

Esfuerzo de captura: El modelo asintótico de $\mathrm{ChaO}_{2}$ (Colwell y Coddington 1994, León-Cortés et al. 1998) indicó que la riqueza potencial en la Sierra de Huautla es de 154 especies; en la Fig. 1 se ilustra esta tendencia $\left(\mathrm{ChaO}_{2}\right)$. El esfuerzo de captura total efectuado en la sierra de Huautla fue de 1668 horas/ persona.

El tiempo de permanencia en cada sitio fue de cuatro horas en cada visita, pero el número de días de recolecta y la cantidad de recolectores (entre dos y seis personas) fueron variables; por ejemplo, en las localidades de Chiautla, Tlancualpicán, Los Linderos, Teotlalco y Jolalpan se efectuó el mayor esfuerzo de captura con más de 100 horas/persona (Cuadro 3). En este cuadro también se aprecia que al utilizar otros estimadores se obtuvieron resultados diferentes a los encontrados con $\mathrm{Chao}_{2}$ (Fig. 2): 194 especies con el modelo de Clench (1979) y 144 con el exponencial; aunque el logarítmico no calcula un valor para la asíntota, permite observar cuánto falta por recolectar. Cuando se evaluó cada opción de acuerdo con Díaz-Francés y Soberón (2005), se encontró que la curva con mayor éxito fue la logarítmica, después y con poca diferencia la de Clench, y al final la exponencial.

Riqueza por familia: En México existen aproximadamente 1200 especies de Papilionoidea (Luis et al. 2003b) repartidas en cuatro familias, siendo Nymphalidae la de mayor diversidad (43.37\%), Lycaenidae (42.32\%), Pieridae $(8.85 \%)$ y Papilionidae

CUADRO 2

Número de especies de Papilionoidea en los estados con mayor riqueza

TABLE 2

Species of Papilionoidea in richest Mexican states

\begin{tabular}{|c|c|c|c|c|c|c|c|c|c|c|c|}
\hline Familia & CHIS & OAX & VER & GRO & JAL & $\mathrm{COL}$ & QROO & DGO & $\mathrm{BC}$ & $\mathrm{BCS}$ & MOR* \\
\hline Pieridae & 70 & 64 & 57 & 44 & 44 & 36 & 27 & 19 & 26 & 27 & 36 \\
\hline Nymphalidae & 379 & 371 & 300 & 209 & 176 & 135 & 116 & 61 & 34 & 23 & 125 \\
\hline Lycaenidae & 333 & 285 & 279 & 192 & 151 & 125 & 64 & 45 & 53 & 30 & 112 \\
\hline Total & 824 & 771 & 676 & 477 & 399 & 324 & 231 & 137 & 121 & 86 & 297 \\
\hline
\end{tabular}

CHIS: Chiapas; OAX: Oaxaca; Ver: Veracruz: GRO: Guerrero; JAL: Jalisco: COL: Colima; QRO: Quintana Roo; DGO: Durango; BC: Baja California; BCS: Baja California Sur; MOR: Morelos. Datos tomados de Luis et al. 2003b y Luna-Reyes $2007(*)$. 
CUADRO 3

Esfuerzo de captura efectuado en cada localidad

TABLE 3

Capture effort realizaed in each locality

\begin{tabular}{|c|c|c|c|c|c|c|c|c|c|c|c|c|c|c|}
\hline \multirow{2}{*}{ Localidades } & \multicolumn{12}{|c|}{ Meses } & \multirow{2}{*}{$\begin{array}{c}\text { horas/ } \\
\text { persona }\end{array}$} & \multirow{2}{*}{$\begin{array}{c}\text { No. } \\
\text { visitas }\end{array}$} \\
\hline & $\mathrm{E}$ & $\mathrm{F}$ & M & A & M & $\mathrm{J}$ & $\mathrm{J}$ & A & $\mathrm{S}$ & $\mathrm{O}$ & $\mathrm{N}$ & $\mathrm{D}$ & & \\
\hline Chiautla & 1 & 1 & 1 & 2 & 3 & & 2 & & & 2 & 1 & & 251 & 13 \\
\hline Tlancualpicán & 1 & 2 & & 2 & 2 & & 1 & & & 1 & 1 & 2 & 218 & 12 \\
\hline Los Linderos & & & 2 & 2 & 2 & & & & & & & & 126 & 6 \\
\hline Teotlaco & & & 1 & & 1 & 1 & 1 & & & 1 & 1 & 1 & 120 & 7 \\
\hline Jolalpan & & & 2 & 1 & 2 & & & & & & & & 120 & 5 \\
\hline Atlacahualoya & & & & 2 & 2 & & & & & & & & 96 & 4 \\
\hline El Tepehuaje & & & & 1 & 1 & & & & 1 & 1 & 1 & & 90 & 5 \\
\hline El Limón & & & & 1 & 1 & & & 2 & 1 & & & & 76 & 5 \\
\hline Huehuetlán & 1 & & 1 & & & & 1 & & & & 1 & & 71 & 4 \\
\hline Agua Fría & & & & & 1 & & & 2 & 2 & 2 & & & 70 & 7 \\
\hline Los Sauces & & & & 1 & 1 & 1 & & 1 & & & 1 & & 58 & 5 \\
\hline Ixtlilco El Chico & 1 & & & & & & & & & & & 1 & 56 & 2 \\
\hline Santa María Xuchapa & & 1 & 1 & & & 1 & & & & & & & 42 & 3 \\
\hline Barranca El Almagre & & & 1 & & 1 & & & & & & & & 40 & 2 \\
\hline Pitzotlán & 1 & & & & & & & & & & & & 40 & 1 \\
\hline Ixtlilco El Grande & & & & & & 1 & & & & 1 & & 2 & 36 & 4 \\
\hline Axochiapan & & & 1 & & & & & & & 1 & & & 32 & 2 \\
\hline Chinameca & 1 & & & & & & & & & & & 1 & 28 & 2 \\
\hline Puente Marquéz & & 1 & 1 & & & & & & & & & & 28 & 2 \\
\hline Tepexco & & 1 & 1 & & & 1 & & & & & & & 22 & 3 \\
\hline Santa Cruz Achichipico & 1 & & & & & & & & & & & & 20 & 1 \\
\hline Río Cuautla & & & & & & 1 & & & & & & & 16 & 1 \\
\hline San Miguel Tecolacio & & & & 1 & & & & & & & & & 6 & 1 \\
\hline Viborillas & & 1 & & & & & & & & & & & 6 & 1 \\
\hline Esfuerzo/mes & 168 & 106 & 226 & 218 & 341 & 84 & 85 & 56 & 48 & 136 & 112 & 88 & 1668 & 98 \\
\hline No. horas/mes & 36 & 35 & 52 & 46 & 71 & 24 & 17 & 28 & 24 & 44 & 32 & 29 & 438 & \\
\hline Total personas & 9 & 7 & 13 & 14 & 19 & 11 & 5 & 2 & 2 & 7 & 7 & 7 & 103 & \\
\hline No. días/campo & 6 & 6 & 10 & 11 & 13 & 5 & 3 & 4 & 4 & 7 & 5 & 5 & 79 & \\
\hline
\end{tabular}


CUADRO 4

Riqueza y abundancia estandarizada de la Sierra de Huautla y otras localidades de México

TABLE 4

Richness and standarized abundance in Sierra de Huautla and others localities of Mexico

Localidades

Zenzontla y Ahuacapán,

Jal. Vargas et al., 1999

Chorros del Varal, Mich.

Arteaga, 1991

Pedernales, Mich.

Balcázar, 1988

Cañón de Lobos, Mor.

Luna (en preparación)

Sierra de Huautla, Mor. y Pue.

$\begin{array}{ccccccc}\text { Vegetación } & \text { m snm } & \text { Papilionidae } & \text { Pieridae } & \text { Nymphalidae } & \text { Lycaenidae } & \text { Total } \\ \text { BTC } & 800-900 & 18(242) & 281047) & 97(4224) & 77(1211) & 220(6724) \\ \text { BTC y BTS } & 1000 & 17(150) & 251176) & 66(2350) & 63(1166) & 171(4842) \\ \text { BTC y BTS } & 850-110 & 14 & 22 & 63 & 49 & 148(1850) \\ \text { BTC } & 1200 & 14(292) & 351140) & 49(1772) & 45(504) & 143(3708) \\ \text { BTC } & 900-300 & 13(204) & 233325) & 58(4154) & 48(1108) & 142(8790)\end{array}$

BTC: bosque tropical caducifolio; BTS: bosque tropical subcaducifolio (Rzedowski, 1978).

El número fuera del paréntesis corresponde a la riqueza, el interno a la abundancia.

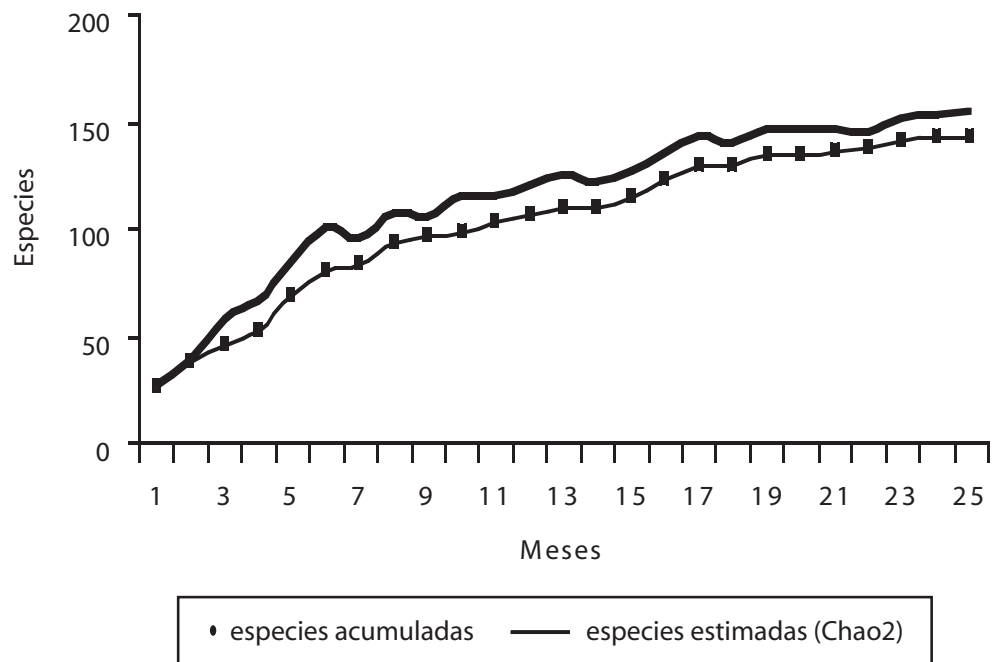

Fig. 1. Curvas de acumulación de especies.

Fig. 1. Species acummulation curves. 
con el menor número de especies (5.51\%). Estos porcentajes se mantienen más o menos constantes (varían entre 5 y $10 \%$ ) en todo el país, con excepción de los estados de la península de Baja California, en los que Lycaenidae tiene el mayor porcentaje de riqueza (Cuadro 2). En la Sierra de Huautla se presenta esta misma proporción para Nymphalidae 41\% (58 especies), una disminución en Lycaenidae $34 \%$ (48) y un aumento considerable en Pieridae 16\% (23) y Papilionidae 9\% (13 especies) (ver lista sistemática).

Riqueza y distribución por localidad: El Tepehuaje es el sitio donde se registró la mayor riqueza (80 spp.) y abundancia estandarizada, a pesar de que en función del esfuerzo de captura esta localidad ocupa el séptimo lugar, después y en orden decreciente: Chiautla (75 spp.), El Limón (66 spp.), Tlancualpicán (64 spp.) y Agua Fría (60 spp.) (Cuadro 6; Fig. 3). Chiautla fue el sitio con mayor esfuerzo de recolecta con
251 horas/persona, siguiéndole Tlancualpicán (218 horas/persona), Linderos (218 horas/persona) y Jolalpan y Teotlalco, ambas con 120 horas/persona. Las tres últimas localidades con menor riqueza son Viborillas (9 spp., 6 horas/ persona), Barranca El Almagre (8 spp., 40 horas/persona) y San Miguel Tecolacio (7 spp., 6 horas/persona).

En cuanto a la distribución por familia, en la mayoría de las localidades se observó la predominancia de Nymphalidae y Lycaenidae y la escasa presencia de Papilionidae, incluso su ausencia en Axochiapan, San Miguel Tecolacio, Atlacahualoya, Río Cuautla, Ixtlilco El Chico, Chinameca, Santa Cruz Achichipico, Viborillas, Puente Marquéz y Santa María Xuchapa (Fig. 3).

Se definieron cuatro grupos de especies de acuerdo con su distribución en el área. El primero incluye a las especies que se presentan en más del 75\% de las localidades (euritópicas), el segundo entre el 50 y $74 \%$, el tercero entre 25 y
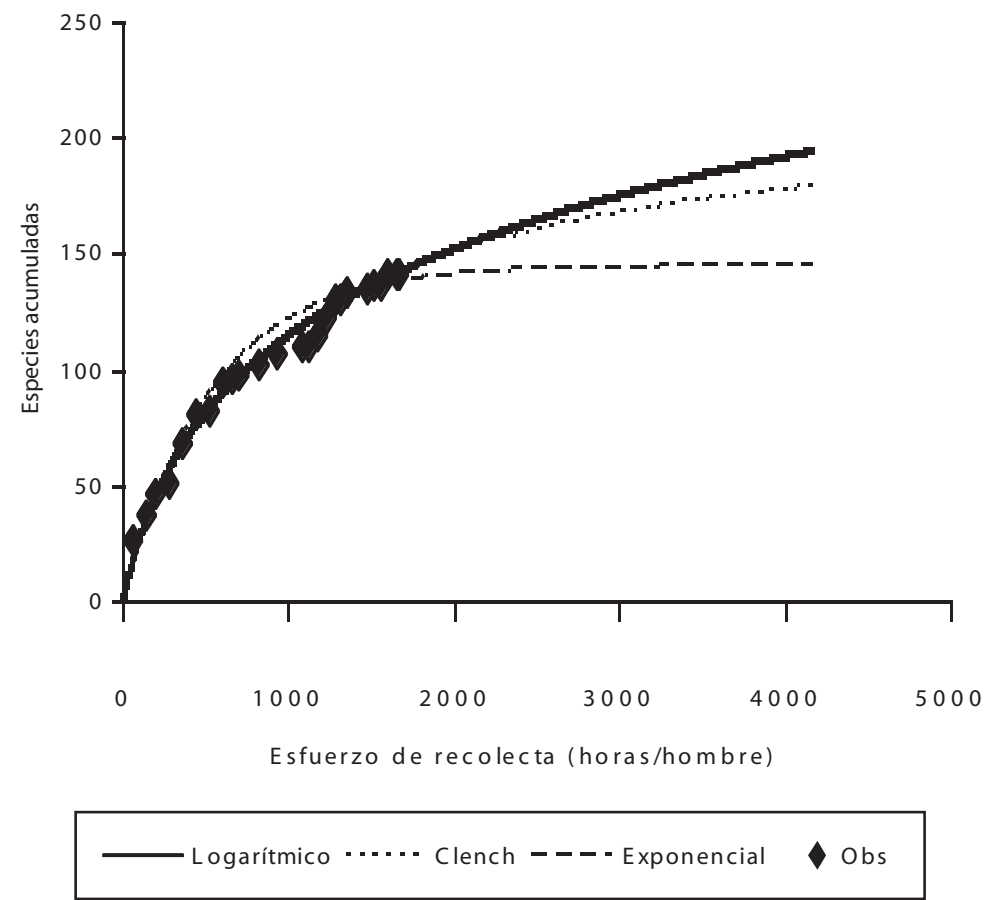

Fig. 2. Modelos de acumulación de especie.

Fig. 2. Models of species acummulation. 


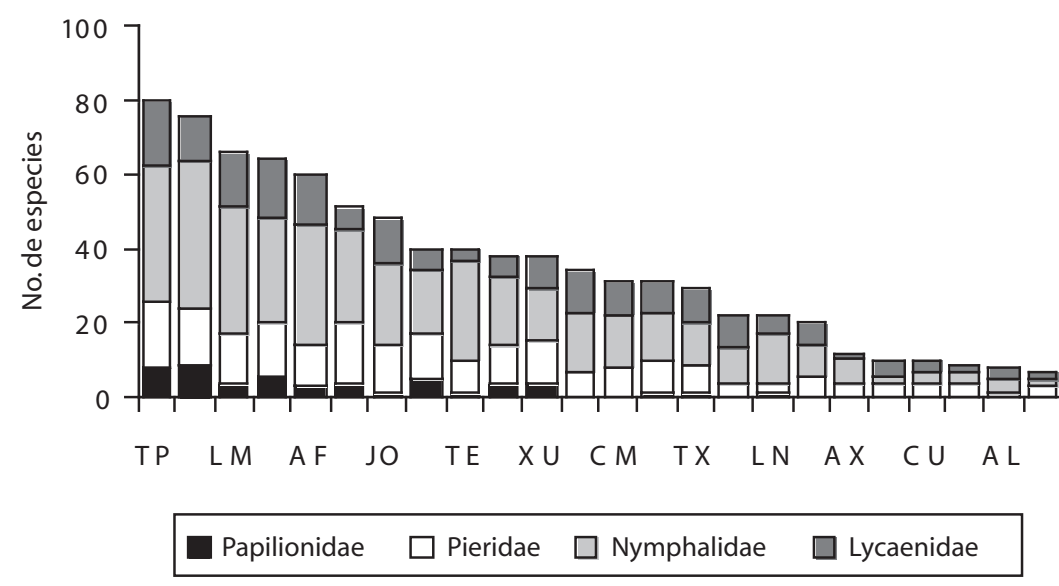

Fig. 3. Distribución de especies por localidad.

Fig. 3. Species distribution by locality.

49\% y el último en menos del 25\% (estenotópicas) (Apéndice I). En el primer grupo se registraron cuatro especies euritópicas: H. hanno, E. daira, P. proterpia y D. gilippus $(24,23,20$ y 19 localidades, respectivamente). El segundo comprende 16 especies (11\% del total: ningún papiliónido). El tercero está conformado por 32 especies (20\%). El último que comprende las estenotópicas, incluye el $66 \%$ de las especies registradas, 31 de estas especies con una distribución restringida a un solo sitio, la mayoría en El Tepehuaje y Chiautla. En este último grupo se incluyó la mayor parte de los licénidos (41 spp.) reconocidos para la sierra de Huautla.

Abundancia total de Papilionoidea: En este análisis, Cañón de Lobos y la sierra de Huautla tuvieron los valores más altos de abundancia estandarizada con respecto a otras localidades con vegetación equivalente (Zenzontla, Ahuacapán) y otros con vegetación de selva baja subcaducifolia (La Calera, Agua Dulce y Platanarillos), a pesar de la gran diferencia del esfuerzo de recolecta que existió entre ellas (Cuadro 5).

Abundancia por familia: La familia más abundante en la sierra de Huautla es
Nymphalidae (4154 ejemplares), y le sigue Pieridae (3324), que consideradas de manera conjunta constituyen el $85 \%$ de los especímenes capturados (Fig. 4); el 15\% restante lo conforman Lycaenidae (1108) y Papilionidae (204 ejemplares).

Abundancia por especie: En la sierra de Huautla los piéridos E. daira, $P$. proterpia, $P$. sennae y $E$. arbela se ubicaron entre las diez especies más abundantes, mientras que 13 especies de licénidos entre las especies raras: C. goodsoni, S. cestri, S. albata, C. stillaticia y L. sessilis (Apéndice I). E. daira y P. proterpia juntas tuvieron más del $22 \%$ del total de los especímenes capturados $(12.27 \%$ y $10.45 \%$ respectivamente), mientras que 118 especies estuvieron representadas cada una por menos del 1\% del total (Fig. 5; Apéndice I). De las seis categorías de abundancia relativa definidas en este trabajo, seis especies fueron muy comunes (MC): E. daira, P. proterpia, H. hanno, $C$. themis, $M$. cyananthe y $P$. sennae; 18 fueron comunes (C), 26 frecuentes (F), 34 escasas (E), 35 raras (R) y 23 muy raras (MR); las tres primeras categorías, MC, C y F contienen el 94\% de los ejemplares recolectados y las restantes tan solo el 6\% del total (Apéndice I; Fig. 6). 
CUADRO 5

Comparativo de riqueza y abundancia de Papilionoidea por localidades

TABLE 5

Comparative Papilionoidea richness and abundance by localities

\begin{tabular}{|c|c|c|c|c|c|}
\hline Localidades & Vegetación & $\begin{array}{l}\text { Esfuerzo de captura } \\
\text { horas/día/persona }\end{array}$ & Riqueza & Abundancia & $\begin{array}{l}\text { Abundancia } \\
\text { estandarizada }\end{array}$ \\
\hline Los Mazos, Jalisco ${ }^{1}$ & BMM & 6027 & 143 & 2544 & 0.42 \\
\hline $\begin{array}{l}\text { Agua Dulce y Platanarillo, } \\
\text { Colima y La Calera, Jalisco }\end{array}$ & STS & 22351 & 281 & 13205 & 0.59 \\
\hline Zenzontla y Ahuacapán, Jalisco ${ }^{1}$ & $\mathrm{SBC}$ & 8064 & 220 & 6724 & 0.83 \\
\hline $\begin{array}{l}\text { Sierra de Huahutla, Morelos- } \\
\text { Puebla }\end{array}$ & $\mathrm{SBC}$ & 1668 & 142 & 8790 & 5.26 \\
\hline Cañón de Lobos, Morelos ${ }^{2}$ & SBC & 392 & 143 & 3708 & 9.45 \\
\hline
\end{tabular}

1: Vargas, et al., 1999: recolecta de ejemplares con trampas y redes; 2: Luna (en prep..); veg: Vegetación: BMM: bosque mesófilo de montaña; STS: selva tropical subcaducifolia; SBC: selva baja caducifolia. Abundancia estandarizada: abundancia/esfuerzo de captura.

Abundancia por localidad: En El Tepehuaje y El Limón se registraron los máximos de abundancia estandarizada, aunque en Agua Fría, Tepexco y San Miguel Tecolacio también se encontraron valores altos (Cuadro 6; Fig. 7).

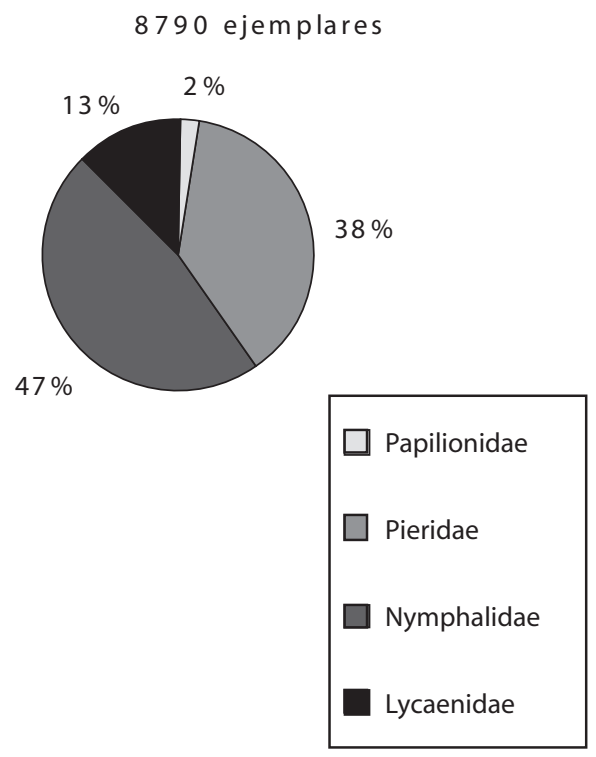

Fig. 4. Abundancia por familia.

Fig. 4. Abundance by family.
Barranca El Almagre, Santa Cruz Achichipico, Axochiapan y Río Cuautla tuvieron la menor abundancia estandarizada de toda el área de estudio.

Fenología: En el análisis de la fluctuación temporal de la comunidad de Papilionoidea se detectaron dos máximos de riqueza, el primero en abril-mayo y el segundo en septiembrenoviembre, así como un valor mínimo en junio (Fig. 8; Apéndice II).

Los valores máximos de abundancia ocurrieron en la época húmeda y cálida, y los menores en la época seca. Se encontró que las especies muy comunes (MC) se presentaron durante todo el año (v. gr. E. daira, P. proterpia, H. hanno, C. themis, M. cyananthe y $P$. sennae), con poblaciones mayores durante la época seca; las especies comunes (C) y frecuentes $(\mathrm{F})$ estuvieron presentes a lo largo del año (v. gr. A. amathea, A. jatrophae, D. eresimus y $P$. agarithe) o solo en una estación (v. gr. seca: M. rubricata, y lluvias: M. elva y T. anomalus, ). En el caso de las especies escasas (E) (H. glauconome, $H$. costaricensis y $P$. epidaus), raras (R) (P. erithalion y R. palegon) y muy raras (MR) (T. weymeri, S. cestri y $P$. 
CUADRO 6

Papilionoidea por localidad de la Sierra de Huatla

TABLE 6

Papilionoidea by locality from Sierra de Huautla

\begin{tabular}{|c|c|c|c|c|c|c|c|c|c|c|c|c|}
\hline \multirow[b]{2}{*}{ Localidad } & \multirow{2}{*}{$\begin{array}{c}\text { Esfuerzo } \\
\text { captura } \\
\text { (horas/ } \\
\text { hombres) }\end{array}$} & \multirow[b]{2}{*}{ Pap } & \multicolumn{3}{|c|}{ Riqueza } & \multirow{2}{*}{ Riqueza } & \multicolumn{5}{|c|}{ Abundancia estandarizada } & \multirow[b]{2}{*}{ Total } \\
\hline & & & Pie & Nym & Lyc & & & Pap & Pie & Nym & Lyc & \\
\hline El Tepehuaje & 90 & 8 & 18 & 36 & 18 & 80 & 1539 & 0,36 & 11,2 & 4,6 & 0,94 & 17,10 \\
\hline Chiautla & 251 & 9 & 15 & 39 & 12 & 75 & 1069 & 0,16 & 1,11 & 2,64 & 0,35 & 4,26 \\
\hline El Limón & 76 & 4 & 13 & 34 & 15 & 66 & 806 & 0,16 & 5,16 & 4,07 & 1,22 & 10,61 \\
\hline Tlancualpicán & 218 & 6 & 14 & 28 & 16 & 64 & 514 & 0,06 & 0,32 & 1,63 & 0,34 & 2,35 \\
\hline Agua Fría & 70 & 3 & 11 & 32 & 14 & 60 & 675 & 1,01 & 3,23 & 4,79 & 0,61 & 9,64 \\
\hline Los Sauces & 58 & 4 & 16 & 25 & 6 & 51 & 344 & 0,09 & 3 & 2,57 & 0,28 & 5,94 \\
\hline Jolalpan & 120 & 1 & 13 & 22 & 12 & 48 & 817 & 0,03 & 0,95 & 4,93 & 0,89 & 6,80 \\
\hline Teotlaco & 120 & 1 & 9 & 27 & 3 & 40 & 323 & 0,01 & 0,98 & 1,63 & 0,08 & 2,70 \\
\hline Ixtlilco El Grande & 36 & 5 & 12 & 17 & 6 & 40 & 250 & 0,31 & 3,72 & 2,53 & 0,39 & 6,95 \\
\hline Huehuetlán & 71 & 4 & 10 & 18 & 6 & 38 & 246 & 0,08 & 1,9 & 1,34 & 0,14 & 3,46 \\
\hline Santa María Xuchapa & 42 & 4 & 11 & 14 & 9 & 38 & 245 & 0,14 & 1,71 & 2,64 & 1,33 & 5,82 \\
\hline Ixtlilco El Chico & 56 & 0 & 7 & 16 & 11 & 34 & 272 & 0 & 1,95 & 0,96 & 1,95 & 4,86 \\
\hline Chinameca & 28 & 0 & 8 & 14 & 9 & 31 & 156 & 0 & 2,32 & 1,43 & 1,82 & 5,57 \\
\hline Pitzotlán & 40 & 1 & 9 & 13 & 8 & 31 & 169 & 0,03 & 2,33 & 1,25 & 0,63 & 4,24 \\
\hline Tepexco & 22 & 1 & 8 & 11 & 9 & 29 & 177 & 0,05 & 2,73 & 1,36 & 3,91 & 8,05 \\
\hline Atlacahualoya & 96 & 0 & 4 & 9 & 9 & 22 & 244 & 0 & 1,11 & 0,57 & 0,85 & 2,53 \\
\hline Los Linderos & 126 & 1 & 3 & 13 & 5 & 22 & 612 & 0,01 & 0,33 & 4,21 & 0,3 & 4,85 \\
\hline Puente Marquéz & 28 & 0 & 6 & 8 & 6 & 20 & 104 & 0 & 1,11 & 0,96 & 1,64 & 3,71 \\
\hline Axochiapan & 32 & 0 & 4 & 7 & 1 & 12 & 57 & 0 & 0,63 & 0,78 & 0,38 & 1,79 \\
\hline Santa Cruz Achichipico & 20 & 0 & 4 & 2 & 4 & 10 & 32 & 0 & 0,95 & 0,15 & 0,5 & 1,60 \\
\hline Río Cuautla & 16 & 0 & 4 & 3 & 3 & 10 & 30 & 0 & 0,56 & 0,56 & 0,75 & 1,87 \\
\hline Viborillas & 6 & 0 & 4 & 3 & 2 & 9 & 19 & 0 & 0,67 & 0,83 & 1,67 & 3,17 \\
\hline Barranca El Almagre & 40 & 0 & 1 & 4 & 3 & 8 & 45 & 0 & 0,13 & 0,35 & 0,65 & 1,13 \\
\hline San Miguel Tecolacio & 6 & 0 & 3 & 2 & 2 & 7 & 45 & 0 & 6,5 & 0,33 & 0,67 & 7,50 \\
\hline Total & 1668 & 13 & 23 & 58 & 48 & 142 & 8790 & 0.12 & 1.99 & 2.49 & 0.66 & 5.27 \\
\hline
\end{tabular}




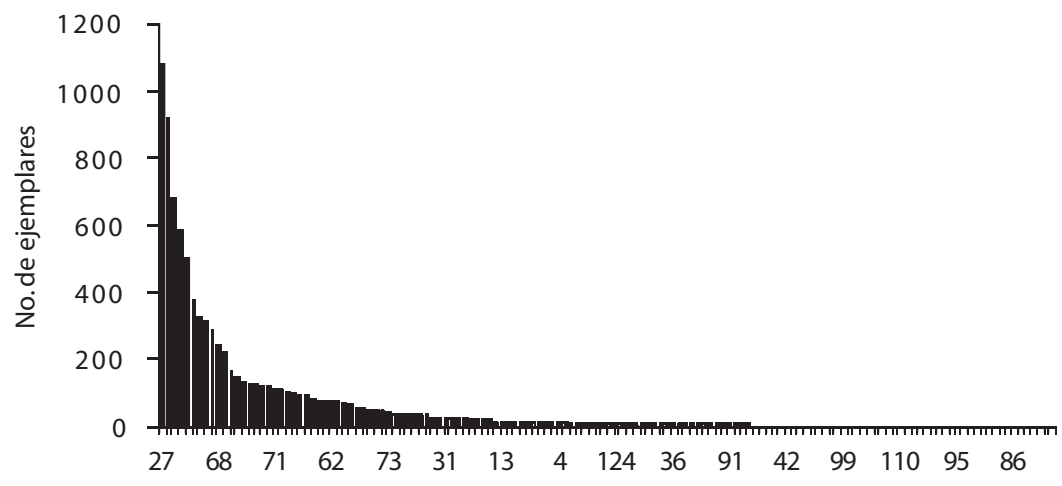

No. de especie

Fig. 5. Abundancia por especie.

Fig. 5. Abundance by specie.

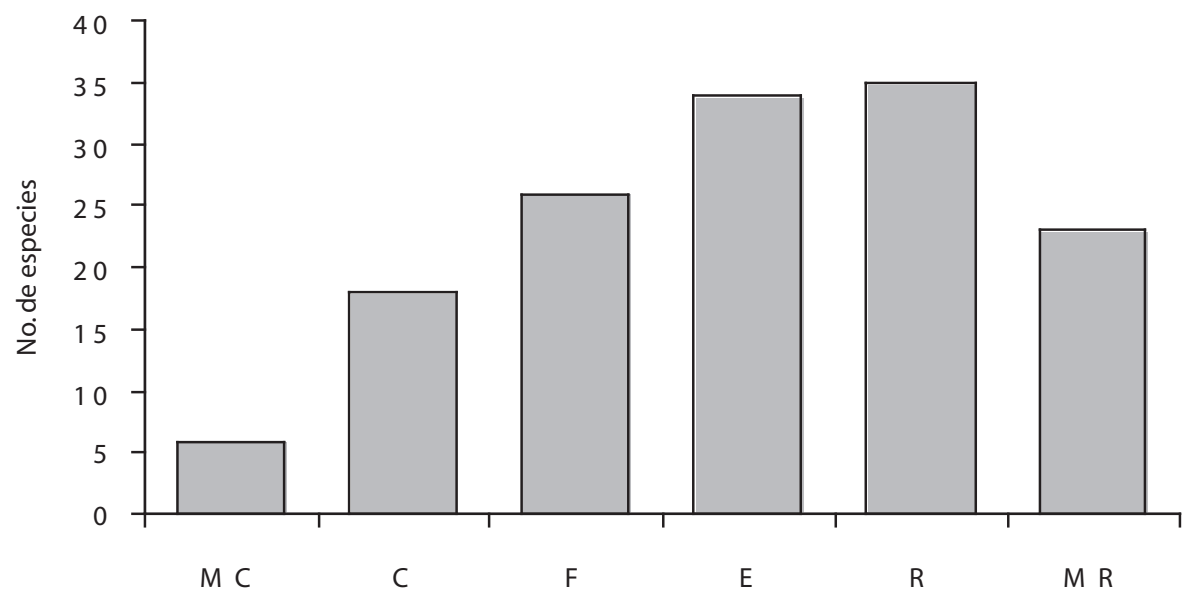

Fig. 6. Categorías de abundancia. MC: muy común; C: común; F: frecuente; E: escasa; R: rara; MR: muy rara.

Fig. 6. Abundance category. MC: very common; C: common; F: frequent; E: scarce; R: rare; MR: very rare.

bithias), se encontró que su presencia mensual varió entre el $45 \%$ (mayo) al 23\% (junio); más del $40 \%$ de las especies de estas categorías están presentes en mayo, septiembre y octubre, y más del $30 \%$ durante seis meses, lo que significa que estas especies definen la variación estacional en la sierra de Huautla.

En las figuras 9 a 12 se muestra la fenología y la curva de acumulación de especies de las localidades en donde se efectuó mayor esfuerzo de recolecta (horas/persona) y más visitas por mes (Chiautla, Tlancualpicán, Teotlalco y El Tepehuaje); en estas figuras, se observa claramente que la riqueza fue mayor durante los meses húmedos (octubre-noviembre).

\section{DISCUSIÓN}

Lista sistemática y riqueza: Desde finales del siglo XIX, más del $90 \%$ de las recolectas en México se han efectuado en las áreas húmedas, principalmente en los bosques tropicales 


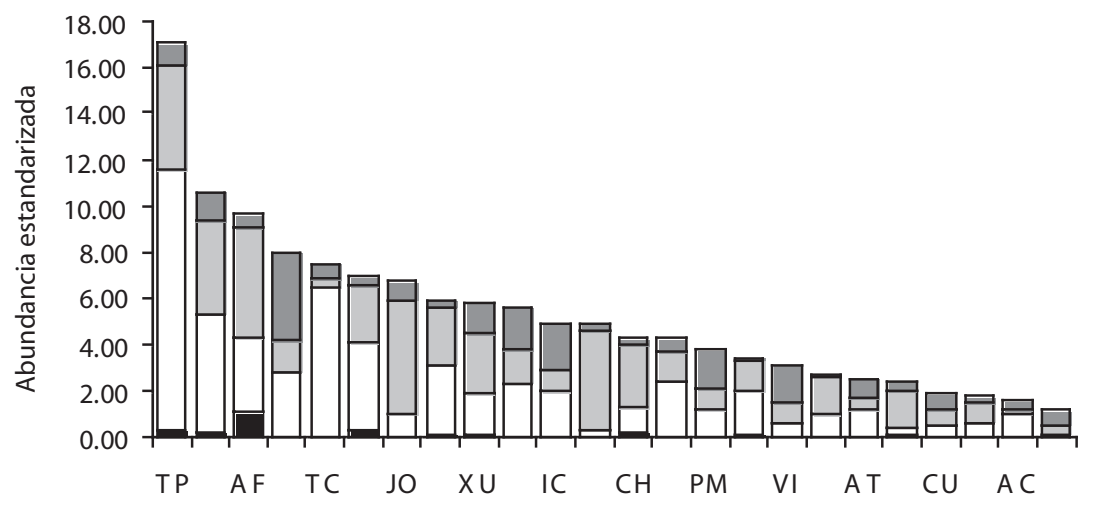

- Papilionidae $\square$ Pieridae $\square$ Nymphalidae $\square$ Lycaenidae

Fig. 7. Distribución de Papilionoidea por localidad.

Fig. 7. Papilionoidea distribution by locality.

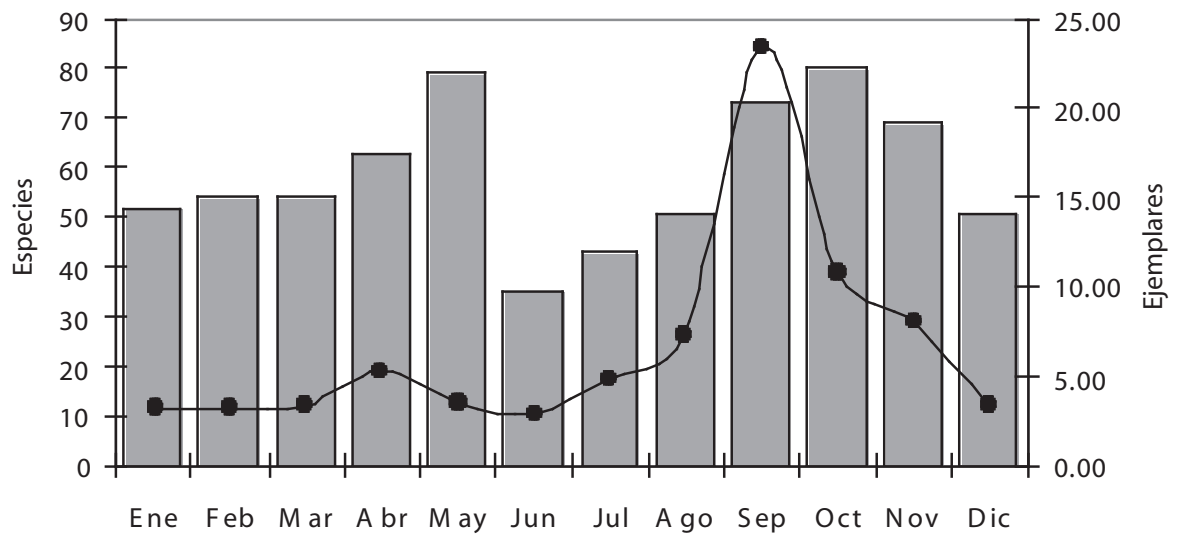

Riqueza $\longrightarrow$ Abundancia estandarizada

Fig. 8. Fenología de Papilionoidea en la Sierra de Huautla.

Fig. 8. Papilionoidea phenology in Sierra de Huautla. 


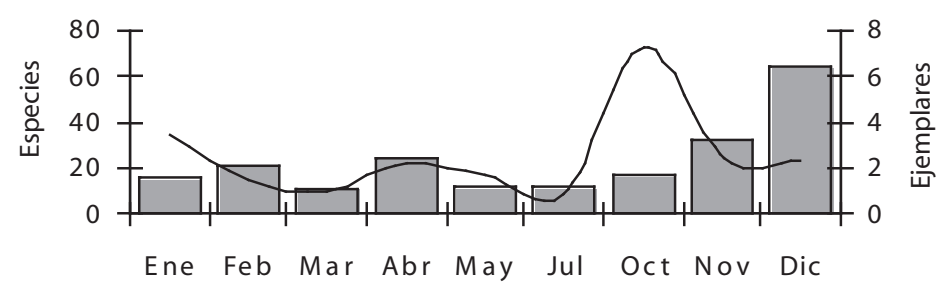

$\square$ R iqueza $\longrightarrow$ A bundancia estandarizada

\section{B. Tlancualpicán}

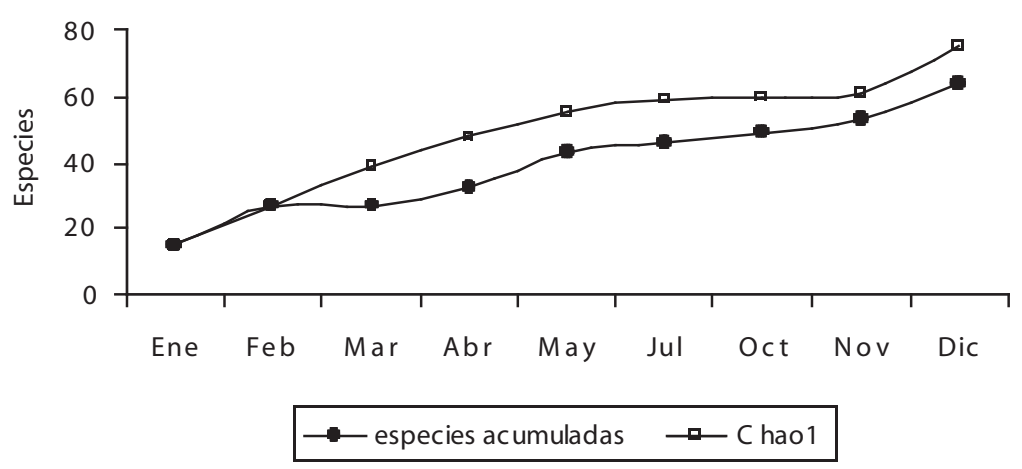

Fig. 9. Fenología (A) y curvas de acumulación de especies (B) de las localidades más visitadas: Tlancualpicán y Chiautla.

Fig. 9. Phenology (A) and species accumulation curves (B) of most visited localities: Tlancualpicán and Chiautla.

perennifolios del sur y sureste (Salinas et al. 2004) y en los bosques mesófilos de montaña (Luis et al. 2003b). En las áreas con clima semicálido y subhúmedo, así como en las áreas templado secas y de coníferas, las recolectas han sido esporádicas y hay un menor número de estudios. Por lo que la lista de especies que se presenta es de gran importancia, ya que se describe la variación estacional y geográfica de Papilionoidea en una comunidad vegetal poco estudiada.

La riqueza de la sierra de Huautla (142 especies) hasta ahora es la menor registrada para un estudio faunístico efectuado en selvas bajas caducifolias y subcaducifolias, a pesar de ser la única que está compuesta por un conjunto de localidades de diferente altitud y distribuidas en dos estados. En el Cuadro 5, se observa que aunque el esfuerzo de recolecta en el área de estudio fue cuatro veces mayor al efectuado en Cañón de Lobos (Luna-Reyes 2007), la diferencia es solo de una especie, a pesar que están situados en una región similar con un solo tipo de vegetación; por el contrario, con La Calera (240 especies), Ahuacapán (197 especies) y Zenzontla (154 especies), Jalisco (Vargas et al. 1999) que se ubican en una región de mayor heterogeneidad altitudinal, 


\section{A. Chiautla}

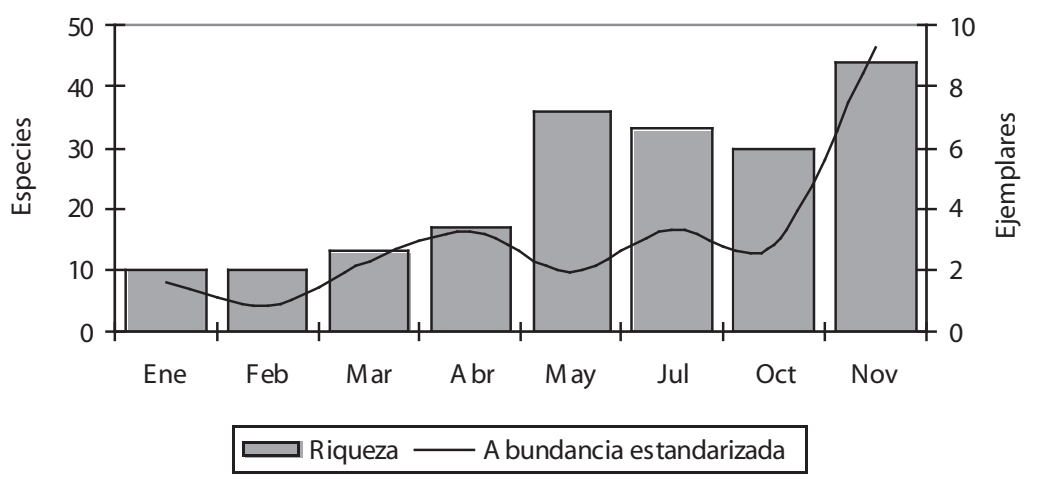

B. C hiautla

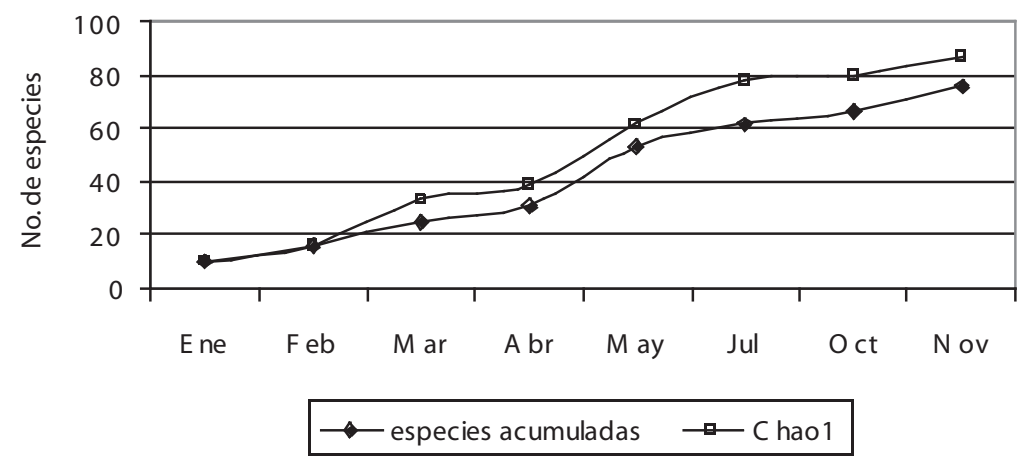

Fig. 10. Fenología (A) y curvas de acumulación de especies (B) de las localidades más visitadas: Teotlalco y El Tepehuaje.

Fig. 10. Phenology (A) and species accumulation curves (B) of most visited localities: Teotlalco y El Tepehuaje.

climática y vegetacional, en donde el esfuerzo empleado fue entre dos y cinco veces mayor al efectuado en la sierra de Huautla, la diferencia con la localidad más rica fue de 98, es decir, $70 \%$ más especies de papilionoideos. Solo Zenzontla presenta selva baja caducifolia y muestra un número de especies cercano a sierra de Huautla.

En México se han realizado muy pocos trabajos en la selva baja caducifolia que describan la distribución estacional y geográfica de la fauna de Papilionoidea, debido a la baja riqueza presente en estas comunidades y a la época seca muy larga y marcada, a pesar de las grandes extensiones que ocupa este ecosistema en todo el país, principalmente en la región del Pacífico. Además de las 142 especies, esta región se caracteriza por la presencia de 18 especies endémicas a México (Apéndice I), valor que proporcionalmente es superior (12.7\%) al encontrado a nivel nacional $(8.66 \%)$; lo que coincide con el hecho que en las zonas áridas y semiáridas se encuentra el mayor número de endemismos (Luis et al. 2003b). 


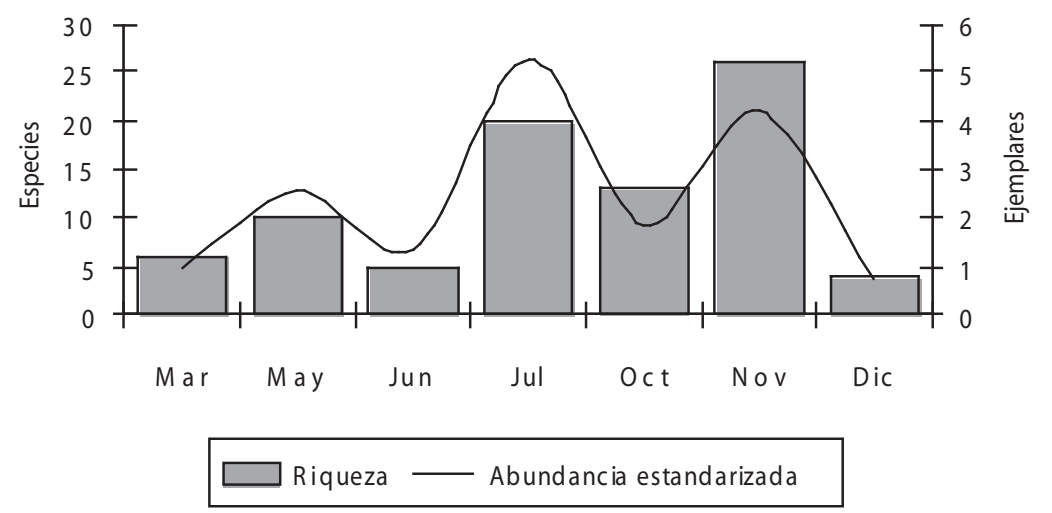

B. Teotlalco

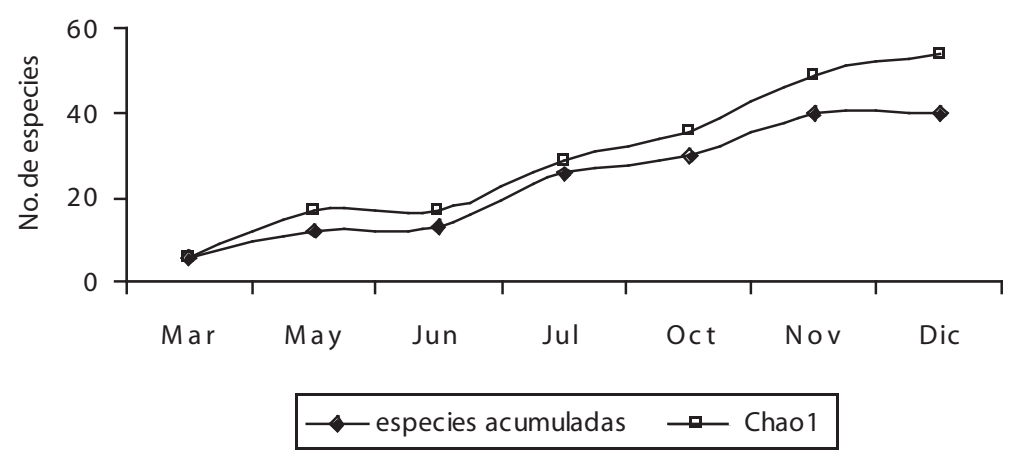

Fig. 11. Fenología (A) y curvas de acumulación de especies (B) de El Teotlalco.

Fig. 11. (A) Phenology and (B) species accumulation curves for Teotlalco.

Con este trabajo la lista de especies de Puebla se incrementó en 25 especies, (ver Apéndice I), debido a que la mayoría de los muestreos previos se habían realizado en el norte del Estado, principalmente en la región húmeda de la Barranca de Patla (área de transición entre selva alta, selva mediana y bosque mesófilo de montaña) y zonas contiguas que han sido recolectadas de forma intensiva, principalmente por aficionados. El resto del Estado ha sido poco o nada explorado (González 1996), incluyendo la parte suroeste que presenta una superficie extensa de selva baja caducifolia donde se localiza la zona de estudio.

Esfuerzo de captura: Los resultados indicaron que la metodología de $\mathrm{Chao}_{2}$ es practicable en recolecciones explorativas o mínimas, pero no en aquellas sistemáticas e intensivas como fue este caso. Al considerar el modelo de Clench (1979), se estimó que falta por registrar el $27 \%$ de las especies de la región (aproximadamente 52 especies) (Fig. 2). 


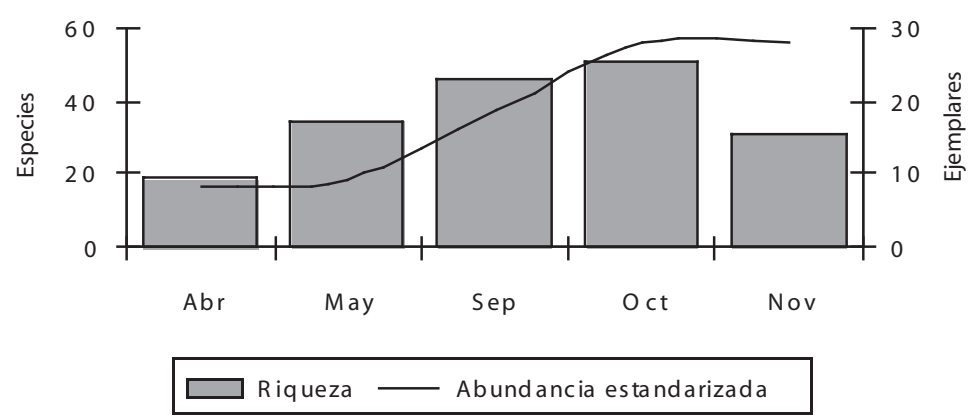

B. EI Tepehuaje

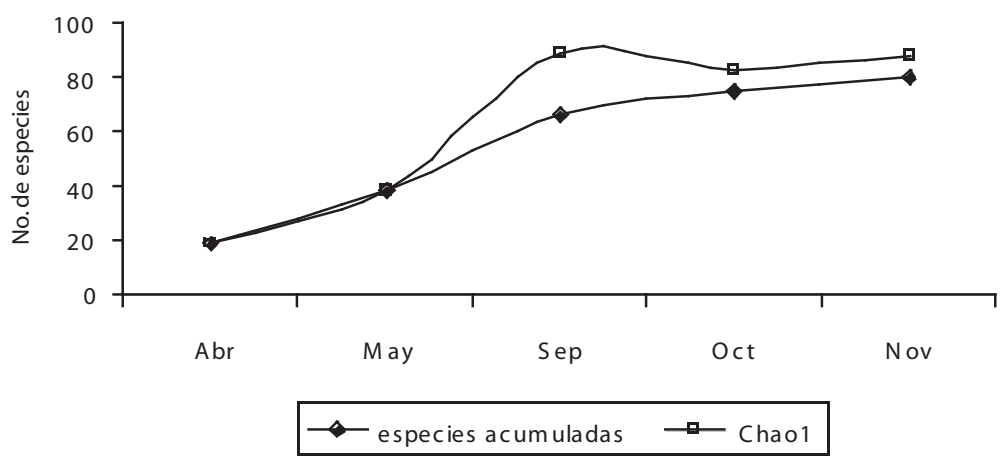

Fig. 12. Fenología (A) y curvas de acumulación de especies (B) de El Tepehuaje.

Fig. 12. (A) Phenology and (B) species accumulation curves for Tepehuaje.

Posiblemente sean especies de Lycaenidae (ver riqueza por familia) que con frecuencia son raras. De las cinco localidades más diversas (Cuadro 5), dos tuvieron un esfuerzo mayor a 200 horas/persona (Chiautla y Tlancualpicán) y tres menor o igual a 90 horas/persona (Agua Fría, El Limón y El Tepehuaje); entre El Tepehuaje y Chiautla con 80 y 75 especies respectivamente, la diferencia es de 161 horas/ persona, o como el caso de Teotlalco que con un esfuerzo de recolecta de 120 horas/persona se registraron únicamente 40 especies. La sierra de Huautla es una unidad biótica homogénea (selva baja caducifolia) y la diferencia entre las localidades se basa en la heterogeneidad de los microhábitats en cada una, lo que afecta de manera directa su riqueza específica; el esfuerzo de captura efectuado en esta gama de microhábitats es esencial para reconocer la riqueza total por localidad y por región.

Riqueza por familia: La riqueza por familia obtenida en este trabajo coincide proporcionalmente con los valores que se dan a nivel nacional y estatal, presentando a Nymphalidae como la más rica y a Papilionidae con la menor diversidad; sin embargo, la proporción para Pieridae se duplica $(16 \%)$ y la de Lycaenidae 
se reduce (8\%) (Cuadro 2). Es posible que el área de distribución promedio de las poblaciones de papiliónidos y piéridos sea más amplia con respecto al de las otras familias en la selva baja caducifolia y subcaducifolia. En México, estos tipos de vegetación se presentan en la región del Pacífico en forma casi continua en la cota altitudinal de los 600 a los $1800 \mathrm{~m}$, lo que favorece su distribución; además, estos resultados podrían indicar que las poblaciones de ninfálidos y licénidos están más restringidas en condiciones extremas. Oñate-Ocaña et al. (2005) señalan que a nivel nacional algunas especies de Papilionidae y Pieridae tienen un área de distribución restringida; sin embargo, local y regionalmente, de acuerdo con los datos obtenidos en este trabajo y el de Luna-Reyes (2007), las áreas de distribución de las especies de estas familias son más amplias que las de Nymphalidae y Lycaenidae; al aplicar el índice que estos autores proponen se esperaría entonces que las especies de Papilionidae y Pieridae de este trabajo tuvieran áreas de distribución mayor. Por otro lado, las especies obtenidas de estas dos últimas familias son muy vágiles y en ocasiones están asociadas con ambientes perturbados (principalmente Pieridae), lo cual es muy común en el área de estudio por la alteración antropogénica acentuada. En el caso particular de los licénidos, su aparente disminución puede deberse al esfuerzo de captura empleado, pues las especies de esta familia requieren un mayor esfuerzo de recolecta, así como una recolecta más orientada o especializada, considerando microhábitats y horarios más específicos para muchos de sus imagos.

Riqueza y distribución por localidad: $\mathrm{La}$ riqueza por localidad depende de la heterogeneidad ecológica que presenta cada una de ellas, pues como se observa claramente en el Cuadro 6, el esfuerzo de captura no es la explicación fundamental, ya que el sitio con mayor riqueza no es aquel en el que se efectuó el mayor esfuerzo de recolecta. Por ejemplo, en una de las localidades más pobres como Barranca El Almagre (8 spp., 40 horas/persona), el esfuerzo de recolecta fue igual al de Pitzotlán que cuenta con 31 especies. Chiautla, El Tepehuaje y El Limón presentan la mayor riqueza y son las localidades donde se observó el menor impacto de las actividades antropogénicas, a pesar que son utilizadas por los habitantes de los poblados aledaños como áreas de cultivo y de pastoreo, principalmente para ganado vacuno. En Tlancualpicán, Jolalpan, Tepexco, Puente Marquéz y Río Cuautla existen cuerpos de agua permanentes (ríos de $10 \mathrm{~m}$ de ancho o más), donde crece vegetación hidrófila abundante y herbáceas cuyas flores son un recurso alimentario importante para los imagos. Otras localidades con cuerpos de agua presentes solo en la época lluviosa son Huehuetlán, Agua Fría, Atlacahualoya, Ixtlilco El Grande, Ixtlilco El Chico y Santa María Xuchapa. En Los Sauces, Los Linderos y Barranca El Almagre se ubican cañadas donde la humedad propicia una mayor riqueza de especies vegetales; finalmente Axochiapan, Santa Cruz Achichipico, Viborillas y San Miguel Tecolacio corresponden a lugares abiertos con algunas lomas de poca pendiente; estas localidades presentaron los valores más bajos de riqueza (Cuadro 6).

La distribución por familia, coincide con los patrones marcados en otras regiones, en donde las familias más ricas (Nymphalidae y Lycaenidae) son las que predominan, solo destaca el hecho que en el $40 \%$ de las localidades no se registraron especies de la familia Papilionidae.

Abundancia total de Papilionoidea: La característica principal de las selvas bajas es la abundancia alta de varias especies de Papilionoidea; sin embargo, en la sierra de Huautla ésta depende básicamente de cinco especies, que en conjunto constituyen del 40 al $60 \%$ de los ejemplares registrados: E. daira, $P$. proterpia, H. hanno, C. themis y M. cyananthe, que conforman el $42.76 \%$ de la abundancia.

Abundancia por familia: En general, las proporciones de abundancia coinciden con trabajos realizados en áreas tropicales, por debajo de los $1800 \mathrm{~m}$ de altitud, en donde la mayoría de las especies de papiliónidos y licénidos 
presentan densidades bajas. Ehrlich (1960) menciona que Lycaenidae es una familia muy diversa pero con poblaciones reducidas, a diferencia de los piéridos que están menos diversificados pero tienen poblaciones mayores, son más conspicuos, y fáciles de recolectar y observar. Además Pieridae se caracteriza por contener especies colonizadoras, que son favorecidas con la perturbación de las selvas bajas, debido a que sus larvas están asociadas a plantas secundarias de gran éxito.

Abundancia por especie: El $65 \%$ de las especies de la sierra de Huautla están representadas por menos de 22 ejemplares cada una de ellas, 23 de las cuales solo por un ejemplar (Fig. 6). Es probable que muchas de estas especies no se vuelvan a recolectar en la zona durante mucho tiempo, ya que su obtención es más casuística debido a su rareza relativa y al hecho de que no se reconoce su status de residencia. El 35\% restante incluye 50 especies, de las cuales más del $70 \%$ de éstas se registrarán año tras año, debido a su abundancia relativa y que a muchas de ellas presentan una o más generaciones anuales. Las especies euritópicas $E$. daira, $P$. proterpia y $H$. hanno fueron las más abundantes en la zona (Apéndice II).

Abundancia por localidad: La abundancia en El Tepehuaje se debe a la gran cantidad de piéridos registrados $v$. gr. P. proterpia (447), E. daira (224), E. arbela (144) y P. sennae (93) los cuales hacen un total de 908 ejemplares que constituyen más del 10\% del total de papilionoideos y el $28.25 \%$ de los piéridos registrados (Cuadro 6; Fig. 7). Estas especies se caracterizan por su amplia distribución, gran vagilidad y versatilidad para adecuarse a los recursos alimentarios disponibles, tanto en su estadio larval, como en el adulto (Courtney 1986). En las localidades donde se registró la menor abundancia, se observó el efecto del impacto humano en el hábitat, pues gran parte del área se ha transformado en tierras de cultivo (maíz, sorgo, jitomate y otros) y zonas de pastoreo para ganado vacuno y ovino, por lo que son frecuentes zonas de vegetación secundaria, con pocos manchones de selva caducifolia original, favoreciendo exclusivamente a los piéridos y afectando directamente a las poblaciones de licénidos.

Fenología: La distribución estacional de la riqueza no coincide con el patrón esperado para un área que presenta un clima cálido subhúmedo con régimen de lluvias de verano muy marcado y una época seca extrema, donde la fenología de la vegetación cambia drásticamente entre la época seca y húmeda, y en la que se esperaría que la riqueza y abundancia de los Papilionoidea varíe de manera similar (Fig. 8; Apéndice II). Lo peculiar de la sierra de Huautla es que la época seca se divide en dos, la primera de diciembre a marzo con un $38 \%$ de la riqueza, bastante alta para una zona semiárida, y la segunda que comprende los meses más secos en la región (abril-mayo) con 44.4 y $55.6 \%$ respectivamente, este último muy similar al de mayor diversidad de la época húmeda (octubre), patrón distinto al encontrado en otras regiones (Luis y Llorente 1990, Luis et al. 1991, Vargas et al. 1992, 1999, Valencia 1999, Pozo et al. 2003), en donde los meses más pobres son abril-mayo, por ser en general los meses más secos. De acuerdo con Balcázar (1988), Arteaga (1991), De la Maza R. et al. (1995a,b), Lara (1999), Vargas et al. (1999) y Luna-Reyes (2007), en los ambientes secos y semisecos el número de especies y de ejemplares se reduce notablemente durante la época seca. Un factor metodológico que influyó a que el patrón de la sierra de Huautla fuera distinto, es el esfuerzo de recolecta entre las dos estaciones, ya que durante la época seca (enero-mayo) se efectuó más del doble (1059 horas/persona) que en la época húmeda (julio-noviembre) (437 horas/persona). Este esfuerzo diferencial mucho mayor en la época seca es único para un trabajo sistemático en México.

La diferencia entre los picos de riqueza en la época seca (marzo-mayo) y húmeda (agostooctubre), es de solo una especie (mayo: 79 especies y octubre: 80 especies). Tal riqueza y similitud principalmente se debe a las 92 especies que ocupan la categoría de Escasas, 
Raras y Muy Raras (Fig. 8), que ocurren durante algunos meses, constituyendo entre el 9 y el $40 \%$ de la riqueza mensual, pero con una representación mayor en mayo (36 spp.). Por el contrario, las especies Muy Comunes y gran parte de las Comunes (60\%) estuvieron presentes todo el año, aunque la mayoría de esta última categoría (más del 90\%) principalmente se concentró en la época húmeda. Estos resultados coinciden con Pozo et al. (2005), quienes consideran que el cambio en la fenología de la fauna de una región se debe a las especies univoltinas y de baja densidad.

A diferencia de la riqueza, la abundancia estandarizada presenta una distribución típica, con el máximo durante la época húmeda y una baja sustancial en la época seca (Fig. 8). Esta marcada estacionalidad de las poblaciones de papilionoideos fue detectada de manera muy clara con los valores de abundancia estandarizada, patrón que se corresponde al encontrado en otros trabajos realizados en zonas de selva baja caducifolia $v$. gr. Chorros del Varal, Michoacán (Arteaga 1991) y Cañón de Lobos, Morelos (Luna-Reyes 2007), incluso con otros desarrollados en ambientes más húmedos como los de sierra de Atoyac (Vargas et al. 1992) y sierra de Manantlán (Vargas et al. 1999).

El análisis de la fenología de los papilionoideos de las localidades más ricas y con mayor abundancia estandarizada (Tlancualpicán, Chiautla, Teotlalco y El Tepehuaje) mostró que la comunidad de mariposas presenta un patrón estacional ya descrito por Wolda (1988).

En áreas tropicales como en la sierra de Huautla, la precipitación puede ser el factor climático determinante en la dinámica de las poblaciones de insectos, especialmente de los fitófagos como las mariposas.

\section{AGRADECIMIENTOS}

Queremos agradecer a todas las personas que ayudaron en el trabajo de campo, quienes hicieron posible este artículo. A Omar Ávalos por su ayuda en la aplicación de los métodos automatizados y sus comentarios al texto. Así como el apoyo recibido de los proyectos
CONABIO R185, DGAPA IN 212006, PAPIME PE 201507y CONACyT 83237. De manera especial a la Comisión Nacional para el Conocimiento y Uso de la Biodiversidad (CONABIO). Un revisor anónimo ayudó a mejorar sensiblemente este trabajo.

\section{RESUMEN}

La Cuenca del Balsas es una región singular donde se encuentra una representación significativa de la riqueza y el endemismo de la flora, la herpetofauna y la avifauna mexicanas. Sin embargo, es escaso el conocimiento respecto a los papilionoideos (Lepidoptera), en especial aquellos asociados con la selva baja caducifolia. Aquí se presenta un estudio sobre la distribución local y temporal de los Papilionoidea de la cuenca alta en su vertiente oriental al río Balsas, en particular de la sierra de Huautla y áreas adyacentes. Se efectuaron 25 periodos de trabajo en campo para 24 localidades de sbc de los estados de Morelos y Puebla, ubicadas en altitudes entre los 900 y $1300 \mathrm{~m}$. Se capturaron 8790 ejemplares que corresponden a 83 géneros y 142 especies de Papilionoidea (sensu Kristensen, 1975: Papilionidae, Pieridae, Nymphalidae y Lycaenidae) 18 endémicas a México, además 25 especies constituyen nuevos registros para Puebla. Con este trabajo, ambos estados se ubican entre los siete más ricos de México. En el análisis de la distribución local de la riqueza y la abundancia de los Papilionoidea, se encontró que la sierra de Huautla es la que presenta la menor riqueza con respecto a otras regiones con sbc y uno de los valores más altos de abundancia estandarizada. El Tepehuaje (Morelos) fue la localidad donde se encontraron los valores máximos de todo el estudio. La lepidopterofauna de la sierra de Huautla presenta un patrón estacional atípico de la riqueza, mientras que su abundancia tiene un comportamiento claramente estacional en el que las poblaciones de papilionoideos fueron bastante mayores durante la época húmeda.

Palabras clave: Bosque tropical, Cuenca del río Balsas, fenología, Mariposas, riqueza, selva baja caducifolia.

\section{REFERENCIAS}

Arita, H.T. \& L. León. 1993. Diversidad de mamíferos terrestres. Ciencias (número especial) 7: 13-22.

Arteaga, G.L.E. 1991. Aspectos de la distribución y fenología de los Papilionoidea (Insecta: Lepidoptera) de la Cañada de los Chorros del Varal, municipio de Los Reyes, Michoacán. Tesis Licenciatura. Escuela de Biología. Universidad Michoacana de San Nicolás de Hidalgo, Morelia, Michoacán, México. 70 p. 
Balcázar, M.A. 1988. Fauna de mariposas de Pedernales, municipio de Tacámbaro, Michoacán (Lepidoptera: Papilionoidea y Hesperioidea). Tesis Licenciatura. Escuela de Biología. Universidad Michoacana de San Nicolás de Hidalgo, Morelia, Michoacán, México. 83 p.

Beccaloni, G.W. \& K.J. Gaston. 1995. Predicting the species richness of neotropical forest butterflies: Ithomiidae (Lepidoptera: Nymphalidae) as indicators. Biol. Conserv. 71: 77-86.

Beutelspacher, C.R. 1984. Mariposas de México. Prensa Médica Mexicana. México D.F., México. 128 p., 20 láminas.

Brown, Jr., K.S. 1997. Diversity, disturbance and sustainable use of Neotropical forest: Insects as indicators for conservation monitoring. J. Ins. Conserv. 1: 1-18.

Clench, H.K. 1979. How to make regional lists of butterflies: some thoughts. J. Lep. Soc. 33: 215-231.

Colwell, R.K. \& J.A. Coddington. 1994. Estimating terrestrial biodiversity through extrapolation. Phil. Trans. R. Soc. London 345: 101-118.

CONABIO. 2000. Sierras de Taxco-Huautla (RTP-120). Regiones Terrestres Prioritarias de México D.F., México.

Courtney, S.P. 1986. The ecology of pierid butterflies: dynamics and interactions. Adv. Ecol. Res. 15: 51-131.

De la Maza, E.R. 1975. Notas sobre lepidópteros de Rancho Viejo y Tepoztlán, Morelos, México. Primera parte: Papilionoidea. Rev. Soc. Mex. Lep. 1: 43-61.

De la Maza, R.R. 1987. Mariposas mexicanas. Fondo de Cultura Económica. México D.F., México. 302 p.

De la Maza, E.R., A. White, \& R. De la Maza. 1995. Exploración de factores compensatorios que permiten el refugio de Rhopalocerofauna hidrófila en cinco cañadas de clima subhúmedo en Morelos, México. Rev. Soc. Mex. Lep. 16: 1-63.

De la Maza, E.R., A. White \& A. Ojeda. 1995. La horofauna hidrófila de la Cañada de la Toma Tilzapotla, Morelos, México (Lepidoptera-Rhopalocera). Rev. Soc. Mex. Lep. 15: 1-35.

DeVries, J.P. 1987. The butterflies of Costa Rica and their natural history. Papilionidae, Pieridae, Nymphalidae. Princeton University, Nueva Jersey, EEUU. 327 p.
Díaz, E. \& J. Soberón. 2005. Statistical estimation and model selection of species-accumulation functions. Conserv. Biol. 19: 569-573.

Ehrlich, P.R. 1960. Lepidoptera, p. 459-473. In McGrawHill. Encyclopedia of Science and Technology. McGraw-Hill, Nueva York, EEUU.

Ehrlich, P.R. \& A.H. Ehrlich. 1961. The Butterflies. Brown, Dubuque, Iowa, EEUU. 262 p.

Emmel, T.C. 1975. Butterflies, their world, their life cycle, their behavior. Knopf, Nueva York, EEUU. 260 p.

Escalante, P., A. Navarro \& T. Peterson. 1993. A geographic, ecological and historical analysis of land bird diversity en Mexico, p. 282-307. In T.P. Ramamoorthy, R. Bye, A. Lot \& J. Fa (eds.). Biological Diversity of Mexico: Origins and Distribution. Oxford, Nueva York, EEUU.

Espinosa, P.H. 1993. Riqueza y diversidad de peces. Ciencias (número especial) 7: 77-84.

Fa, J.E. \& L.M. Morales. 1993. Patterns of Mammalian Diversity in Mexico, p. 319-361. In T.P. Ramamoorthy, R. Bye, A. Lot \& J. Fa (eds.). Biological Diversity of Mexico: Origins and Distribution. Oxford, Nueva York, EEUU.

Feria, P. 1997. Diversidad y distribución avifaunística en una localidad del municipio de Chiautla de Tapia, Puebla. Tesis Licenciatura, Facultad de Estudios Superiores Zaragoza, UNAM, México D.F., México. 66 p.

Flores, V.O. 1993. Riqueza de los anfibios y reptiles. Ciencias (número especial) 7: 33-42.

Flores, V.O. \& P. Gerez. 1994. Biodiversidad y conservación en México: vertebrados, vegetación y uso del suelo. UNAM-CONABIO, México D.F., México. $439 \mathrm{p}$.

García, E. 1981. Modificaciones al Sistema de Clasificación Climática de Köppen. UNAM, México D.F., México. $241 \mathrm{p}$.

González, M.L. 1996. Listado faunístico de los papilionoidea del estado de Puebla, con especial referencia a la zona de Barranca de Patla. Tesis de Licenciatura, Facultad de Ciencias, UNAM, México D.F., México. 112 p.

Hoffmann, C.C. 1940. Catálogo sistemático y zoogeográfico de los lepidópteros mexicanos. Primera parte. Papilionoidea. An. Inst. Biol. UNAM. 11: 639-739. 
Howe, W.H. 1975. The butterflies of Noth America. Doubleday, Nueva York, EEUU. 633 p.

INEGI. 1981. Síntesis Geográfica de Morelos. SPP, México D.F., México.

Krebs, C.J. 1985. Ecología. Estudio de la distribución y abundancia. Harla, México D.F., México. 753 p.

Kristensen, N.P. 1975. Remarks on the family level phylogeny of butterflies (Insecta:Lepidoptera, Rhopalocera). Zool. Syst. Evol. Forsch. 14: 23-33.

Lamas, G. 1984. Los papilionoidea (Lepidoptera) de la Zona reservada de Tambopata, Madre de Dios, Perú. I: Papilionidae, Pieridae y Nymphalidae. Rev. Peruana Ent. 27: 59-73.

Lamas, G. 2000. Estado actual del conocimiento de la sistemática de los lepidópteros, con especial referencia a la Región Neotropical, p. 253-260. In F. Martín, J.J. Morrone \& A. Melic (eds.). Hacia un proyecto para el inventario y estimación de la diversidad biológica en Iberoamérica: PrIBES-2000. SEA. Zaragoza, España.

Lara, A.M.A. 1999. Riqueza de especies y abundancia relativa de la superfamilia Papilionoidea (Lepidoptera) en un bosque de Quercus, en Huitzilac, Morelos. Tesis Licenciatura, Facultad de Estudios Superiores Zaragoza, UNAM, México D.F., México. 69 p.

León, J.L., J. Soberón \& J. Llorente. 1998. Assessing completeness of Mexican Sphinx moths inventories through species accumulation functions (Lepidoptera: Sphingidae). Divers. Distrib. 4: 37-44.

Luis, A. \& J. Llorente. 1990. Mariposas del Valle de México: Introducción e Historia I. Distribución local y estacional de los Papilionoidea de la Cañada de Los Dínamos, Magdalena Contreras, D. F., México. Folia Entomol. Méx. 78: 95-198.

Luis, A., I. Vargas \& J. Llorente. 1991. Lepidopterofauna de Oaxaca I: distribución y fenología de los Papilionoidea de la Sierra de Juárez. Publ. Esp. Mus. Zool. UNAM. 3: 118 .

Luis, A., J. Llorente \& I. Vargas. 2003. Nymphalidae de México I (Danainae, Apaturinae, Biblidinae y Heliconiinae): distribución geográfica e ilustración. CONABIO-UNAM, México D.F., México. 249 p.

Luis, A., J. Llorente, I. Vargas \& A.L. Gutiérrez. 2000. Síntesis preliminar del conocimiento de los Papilionoidea (Lepidoptera: Insecta) de México, p. 275-285. In F. Martín, J.J. Morrone \& A. Melic (eds.). Hacia un proyecto para el inventario y estimación de la diversidad biológica en Iberoamérica: PrIBES-2000. SEA, Zaragoza, España.
Luis, A., J. Llorente, I. Vargas \& A.D. Warren. 2003. Biodiversity and biogeography of Mexican butterflies (Lepidoptera: Papilionoidea and Hesperoidea). Proc. Entomol. Soc. Wash. 105: 209-224.

Llorente, J., A. Luis, I. Vargas \& J. Soberón. 1996. Papilionoidea (Lepidoptera), p. 531-548. In J. Llorente, A.N. García, \& E. González (eds.). Biodiversidad, Taxonomía y Biogeografía de los artrópodos de México: Hacia una síntesis de su conocimiento. UNAM, México D.F., México.

Llorente, J., L. Oñate, A. Luis \& I. Vargas. 1997. Papilionidae y Pieridae de México: distribución geográfica e ilustración. CONABIO-UNAM, México D.F., México. 228 p.

Luna, M.M. 2007. Estudio faunístico sobre Papilionoidea (Lepidoptera) en Cañón de Lobos, Yautepec, Morelos. Tesis de Maestría, Facultad de Ciencias, UNAM, México D.F., México. 102 p.

Martín, F. \& J.M. Lobo. 2000. Diagnóstico sobre el conocimiento sistemático y biogeográfico de tres órdenes de insectos hiperdiversos en España: Coleoptera, Hymenoptera y Lepidoptera, p. 287-308. In F. Martín, J.J. Morrone \& A. Melic (eds.). Hacia un proyecto para el inventario y estimación de la diversidad biológica en Iberoamérica: PrIBES-2000. SEA, Zaragoza, España.

Mittermeier, R.A. \& C. Goettsch. 1992. La importancia de la diversidad biológica de México, p. 63-73. In J. Sarukhán \& R. Dirzo (eds.). México ante los retos de la Biodiversidad. CONABIO, México D.F., México.

Morón, M.A. \& J.E. Valenzuela. 1993. Estimación de la Biodiversidad de Insectos en México; Análisis de un caso. Rev. Soc. Mex. Hist. Nat. 44: 303-312.

Navarro, S.A. \& H. Benítez. 1993. Patrones de riqueza y endemismo de las aves. Ciencias (número especial) 7: 45-54.

Oñate, L., J. Llorente \& J. Meave. 2005. Ideas para un índice de amplitud biogeográfica, p. 189-202. In J. Llorente y J.J. Morrone (eds.). Regionalización biogeográfica en Iberoamérica y tópicos afines. Prensas de Ciencias, Facultad de Ciencias, UNAM, México D.F., México.

Pollard, E. 1977. A method for assessing changes in the abundance of butterflies. Biol. Conserv. 12: 115-134.

Pozo, C., A. Luis, S. Uc, N. Salas \& A. Maya. 2003. Butterflies (Papilionoidea And Hesperoidea) of Calakmul, Campeche, México. Southw. Nat. 48: 505-525. 
Pozo, C., J. Llorente, A. Luis, I. Vargas \& N. Salas. 2005. Reflexiones acerca de los métodos de muestreo para mariposas en las comparaciones biogeográficas, p. 203-215. In J. Llorente \& J.J. Morrone (eds.). Regionalización biogeográfica en Iberoamérica y tópicos afines. Prensas de Ciencias, Facultad de Ciencias, UNAM, México D.F., México

Pyle, R.M. \& A.A. Knopf. 1981. The Audubon Society field guide to North American butterflies. Chanticleer, Nueva York, EEUU. 916 p.

Rzedowski, J. 1992. El endemismo en la Flora Fanerogámica de México, p. 337-359. In G. Halffter (ed.). La Diversidad Biológica de Iberoamérica I. Acta Zool. Mex. Vol. Esp.

Salinas, J.L., A. Luis \& J. Llorente. 2004. Papilionoidea of the evergreen tropical forest of Mexico. Jour. Lep. Soc. 58: 125-142.

Scott, J.A. 1985. The phylogeny butterfly (Papilionidae and Hesperidae). Jour. Res. Lep. 23: 1-60.

Scott, J.A. 1986. The butterflies of North America. A natural history and field guide. Stanford, California, EEUU. 583 p.

Smart, P. 1989. The illustrated Encyclopedia of the butterfly world. Crescent, Nueva York, EEUU. 275 p.

Soberón, J. \& J. Llorente. 1993. The use of species accumulation curves for the prediction of species richness. Conserv. Biol. 7: 480-488.
Trejo, I. \& R. Dirzo. 2000. Deforestation of seasonally dry tropical forest: a national and local analysis in Mexico. Biol. Conserv. 94: 133-142.

Tyler, H., K.S. Brown \& K. Wilson. 1994. Swallowtail butterflies of the Americas. A study in biological dynamics, ecological diversity, biosystematics, and conservation. Scientific Publisher, Gainesville, Florida, EEUU. 376 p.

Valencia, G.M.S. 1999. Listado faunístico de los Papilionoidea (Lepidoptera: Rhopalocera) del derrame lávico del volcán Chichinautzin, Estado de Morelos. Tesis de Licenciatura, Facultad de Ciencias, UNAM, México D.F., México. 46 p.

Vargas, I., J. Llorente \& A. Luis. 1992. Listado lepidopterofaunístico de la Sierra de Atoyac de Álvarez en el estado de Guerrero: notas acerca de su distribución local y estacional (Rhopalocera: Papilionoidea). Folia Entomol. Mex. 86: 41-178.

Vargas, I., J. Llorente \& A. Luis. 1999. Distribución de los Papilionoidea (Lepidoptera: Rhopalocera) de la Sierra de Manantlán (250-1650 m) en los estados de Jalisco y Colima. Publ. Esp. Mus. Zool. UNAM. 11: 153.

Vences, B.M.O. 2004. Lista lepidopterofaunística del estado de Morelos (Insecta: Lepidoptera: Papilionoidea). Tesis de Licenciatura, Facultad de Ciencias, UNAM, 51 p.

Wolda, H. 1988. Insect seasonality: Why? Annu. Rev. Ecol. Syst. 19: 1-18. 


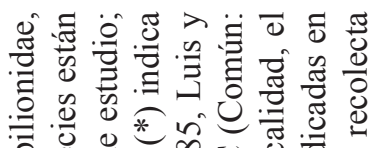

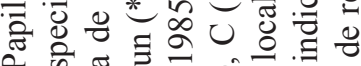
थे के 盛

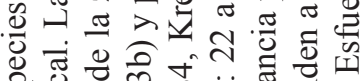

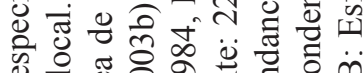
过 অ

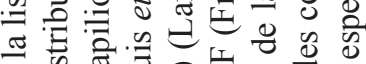

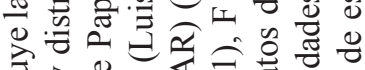

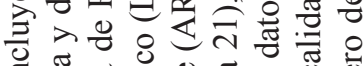
的

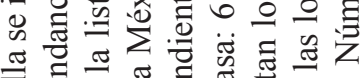
ప

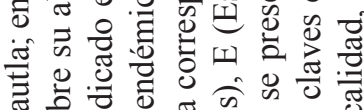

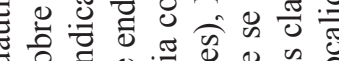
疍

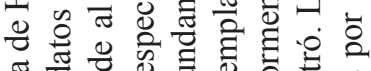

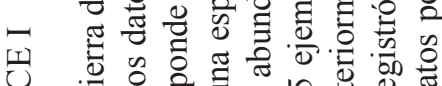

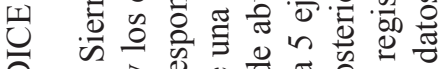
方

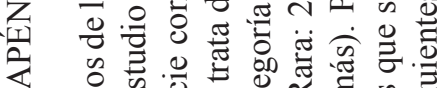

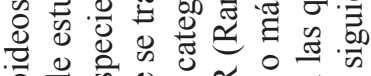

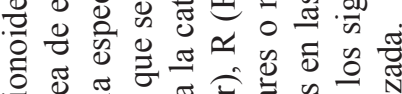

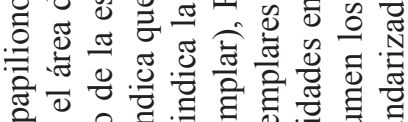

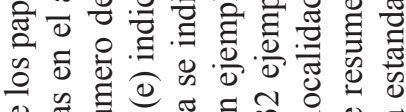

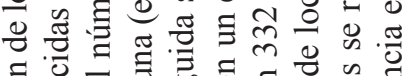

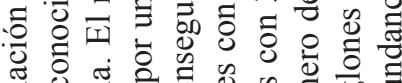

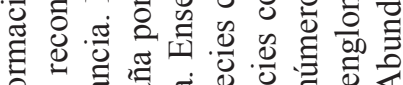

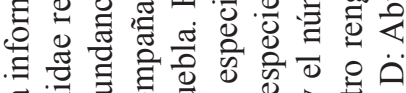
ॠ

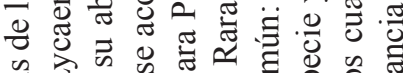

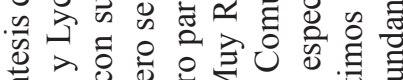

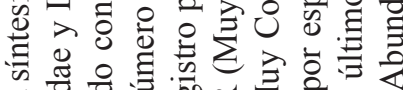

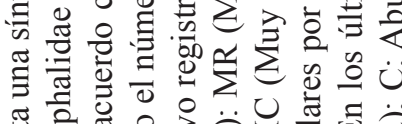

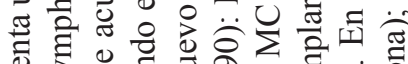

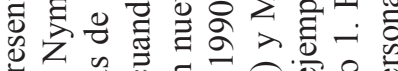

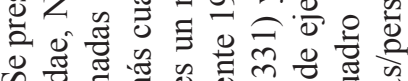

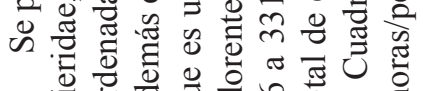

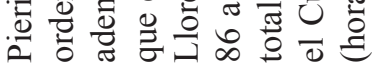

$\stackrel{\leftrightarrow}{\circ}$ ก

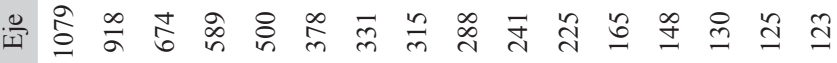

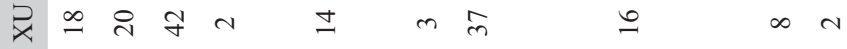

5

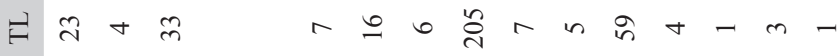

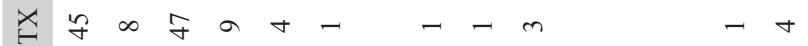

m O m n -

己

$\sum-i$ i $=m$

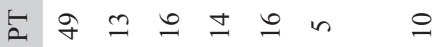

虫

Z

용ำ

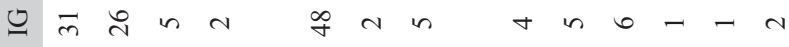

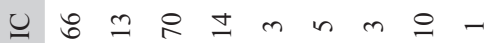

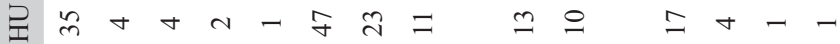

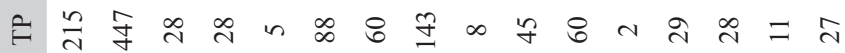

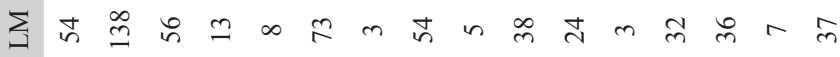

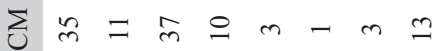

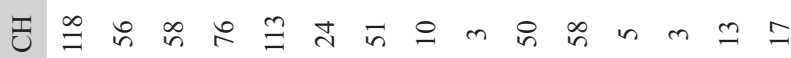

¿n $\pi+N$

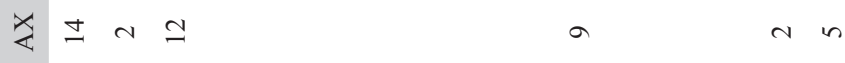

安导一年-

尖守

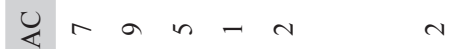

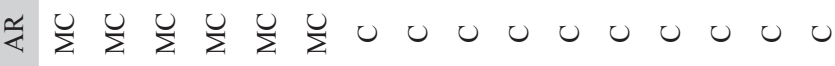

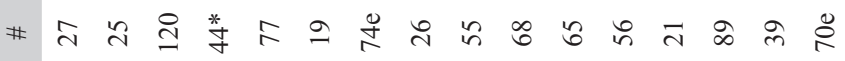




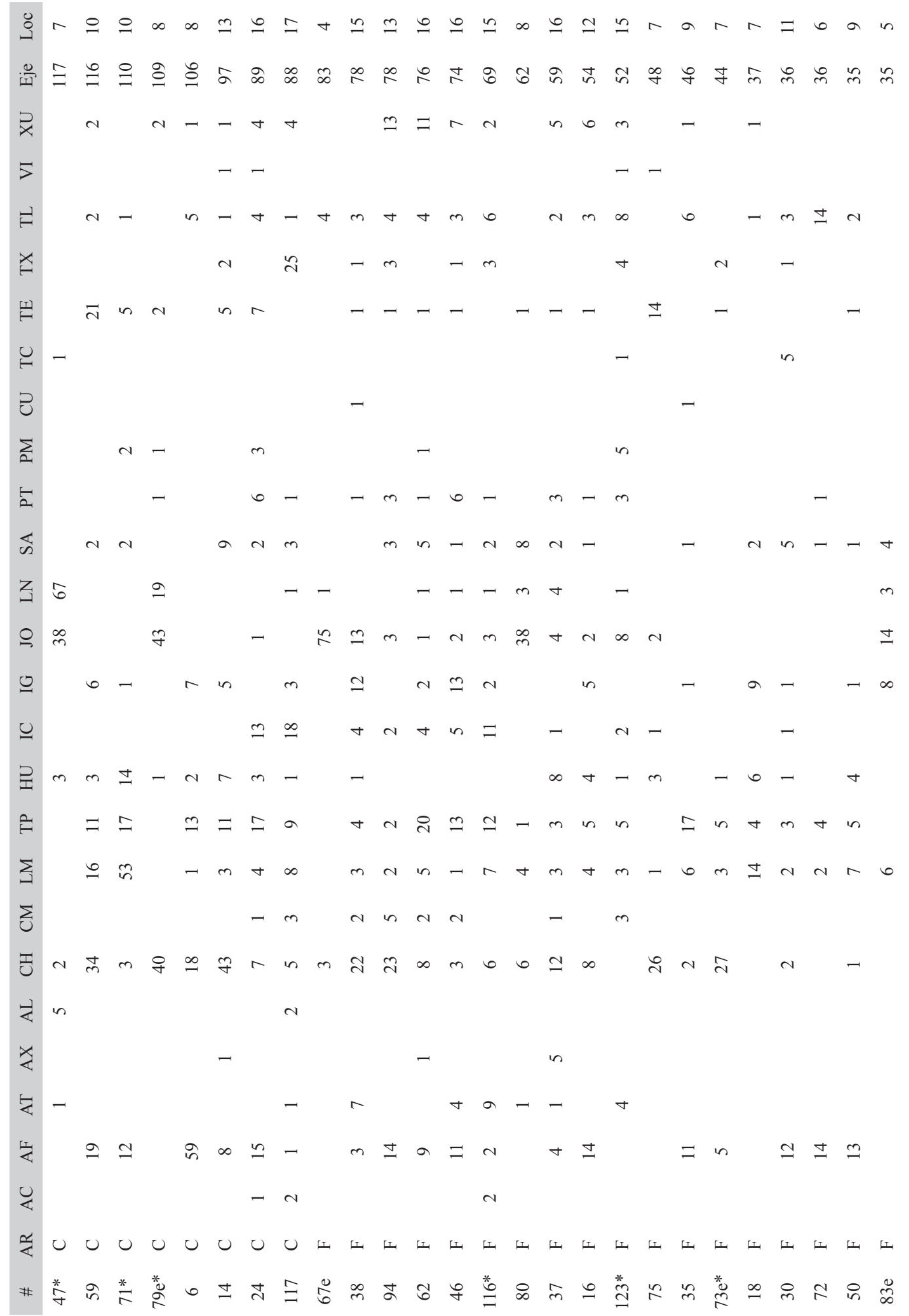




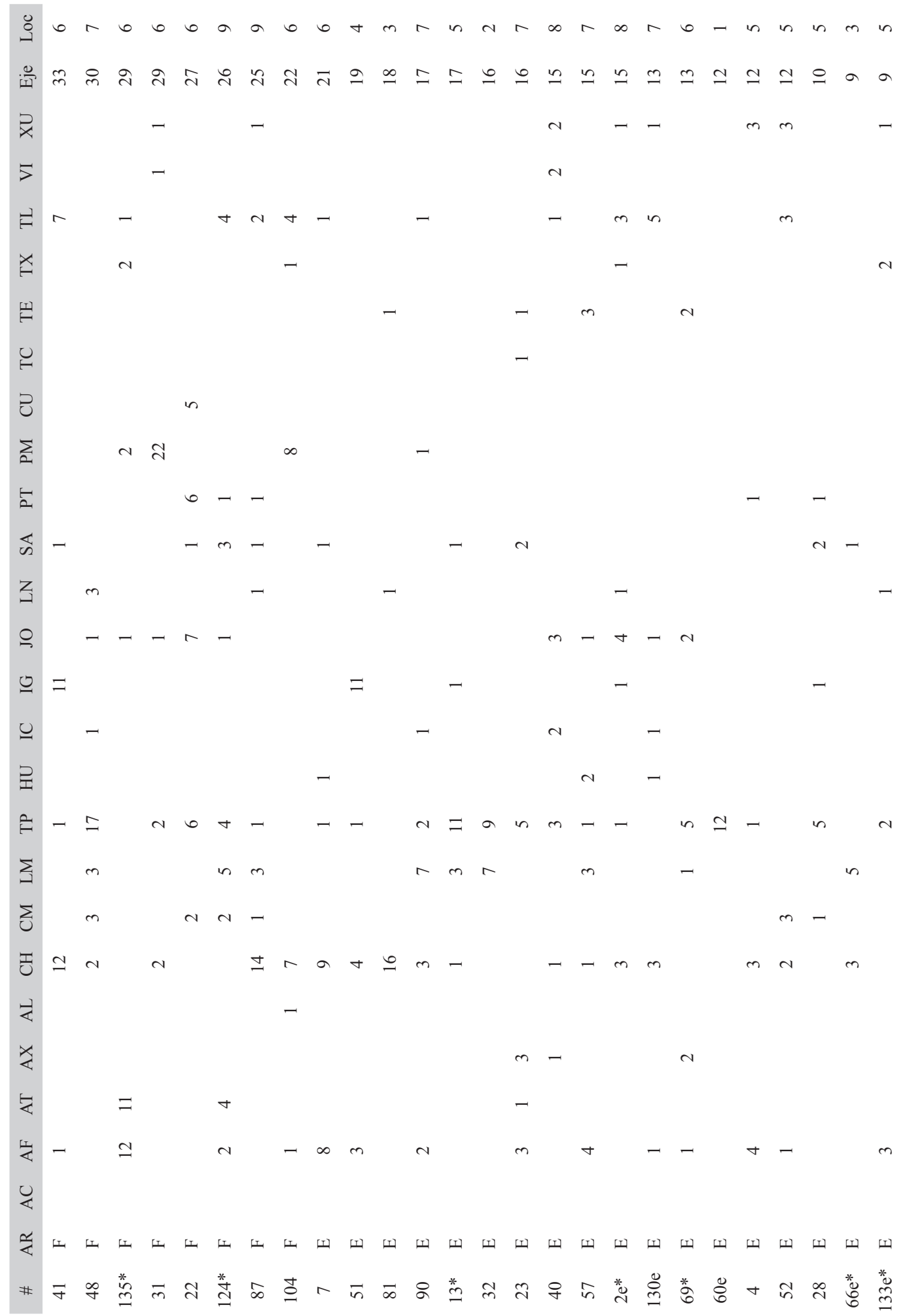




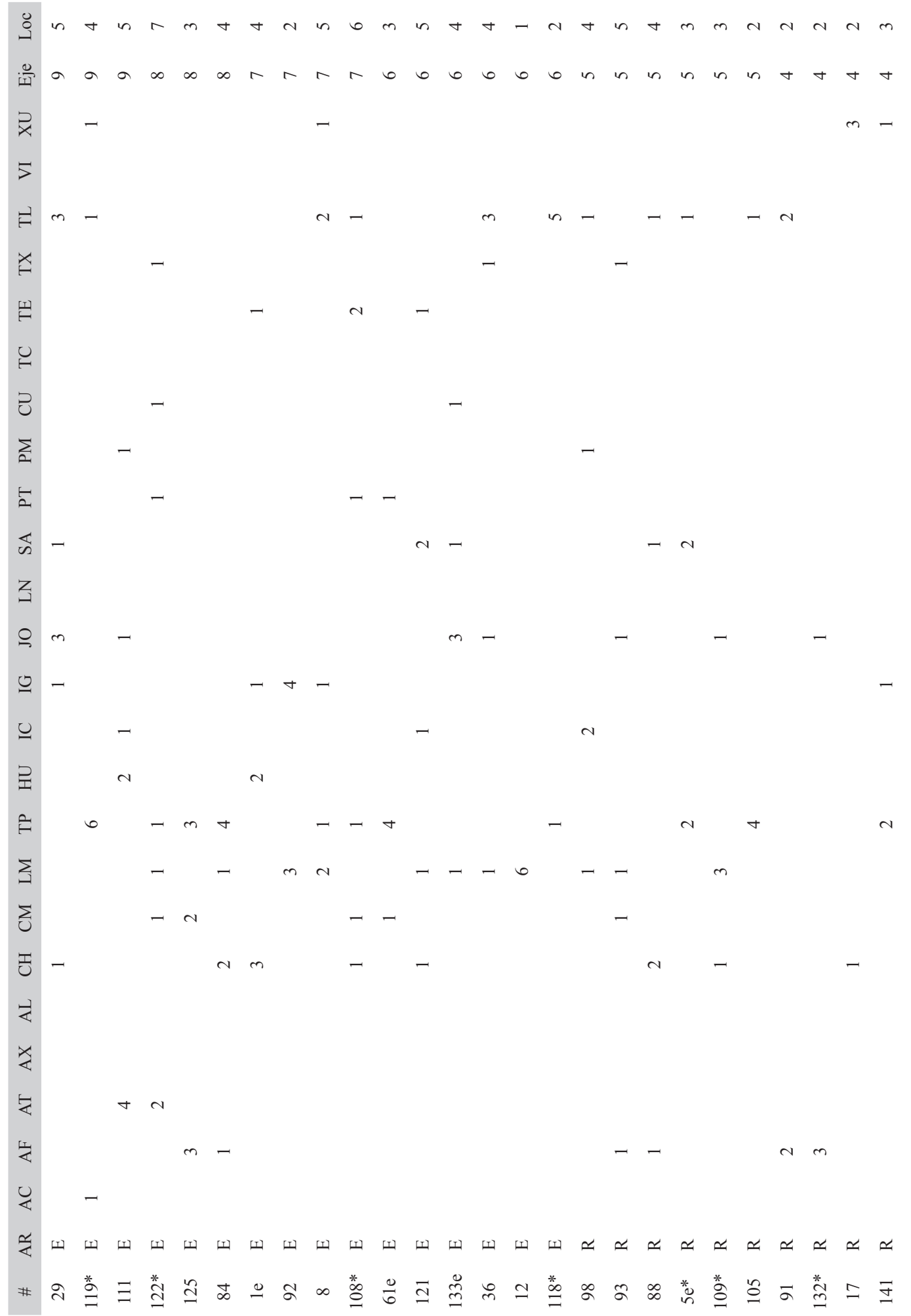




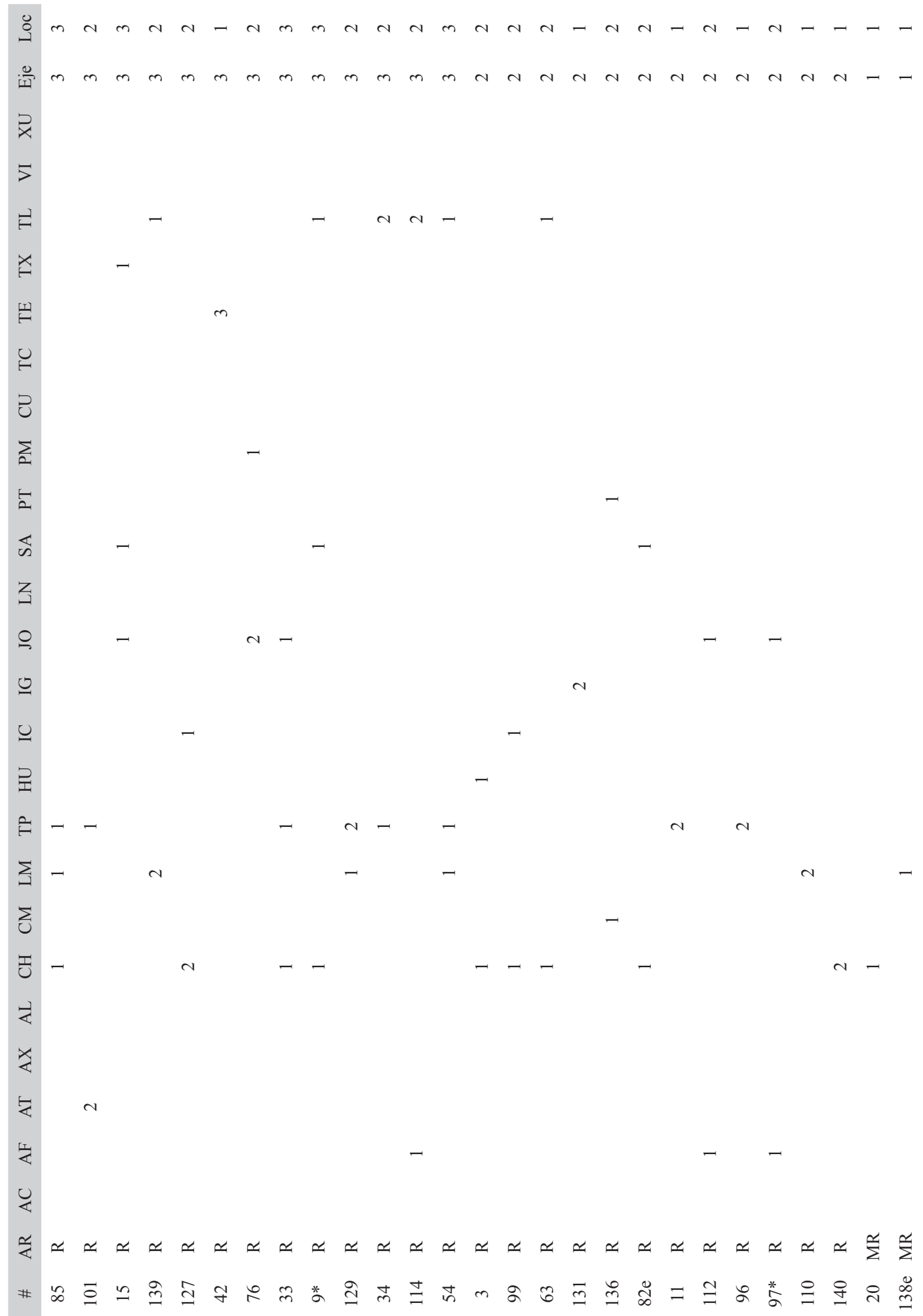




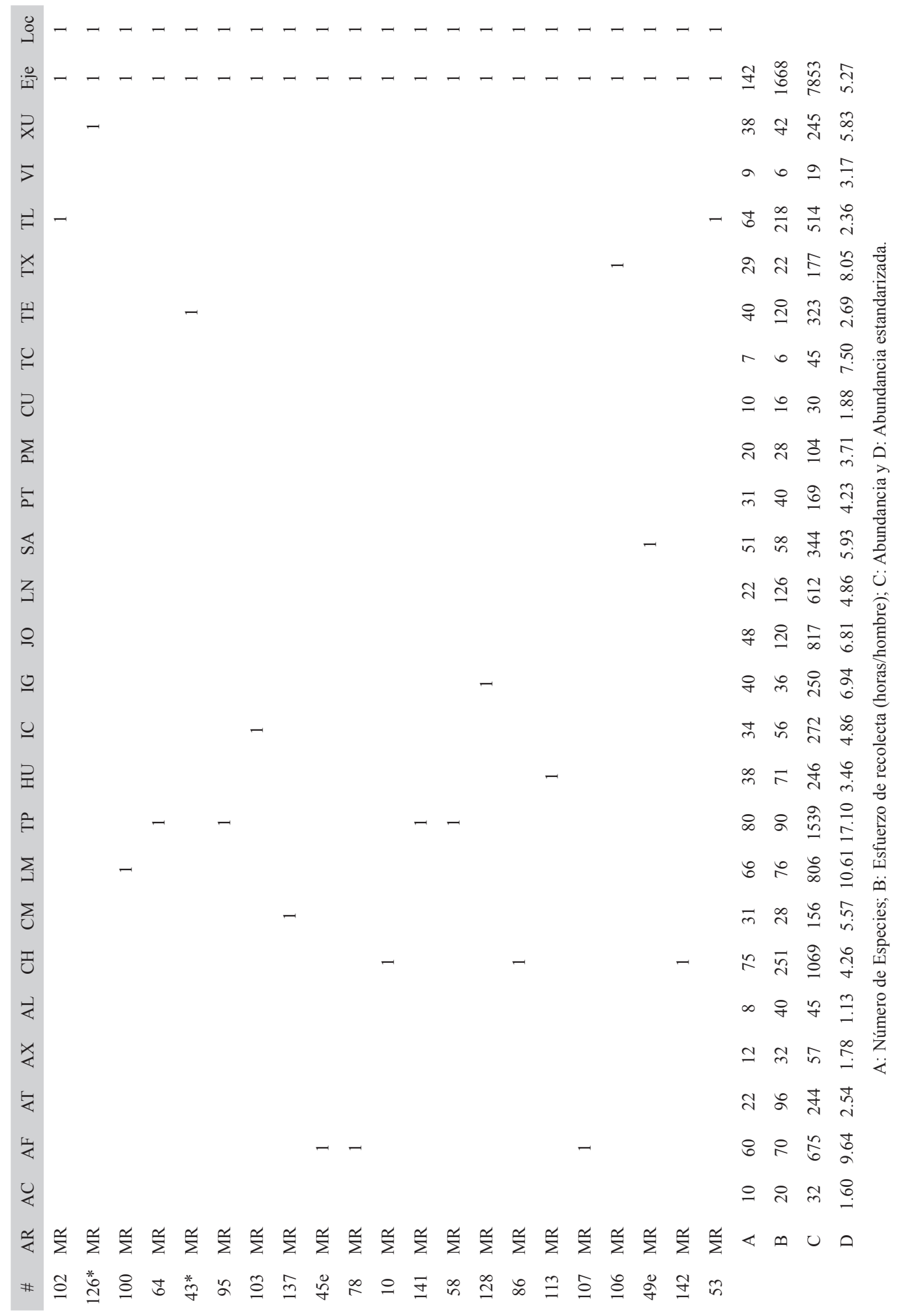




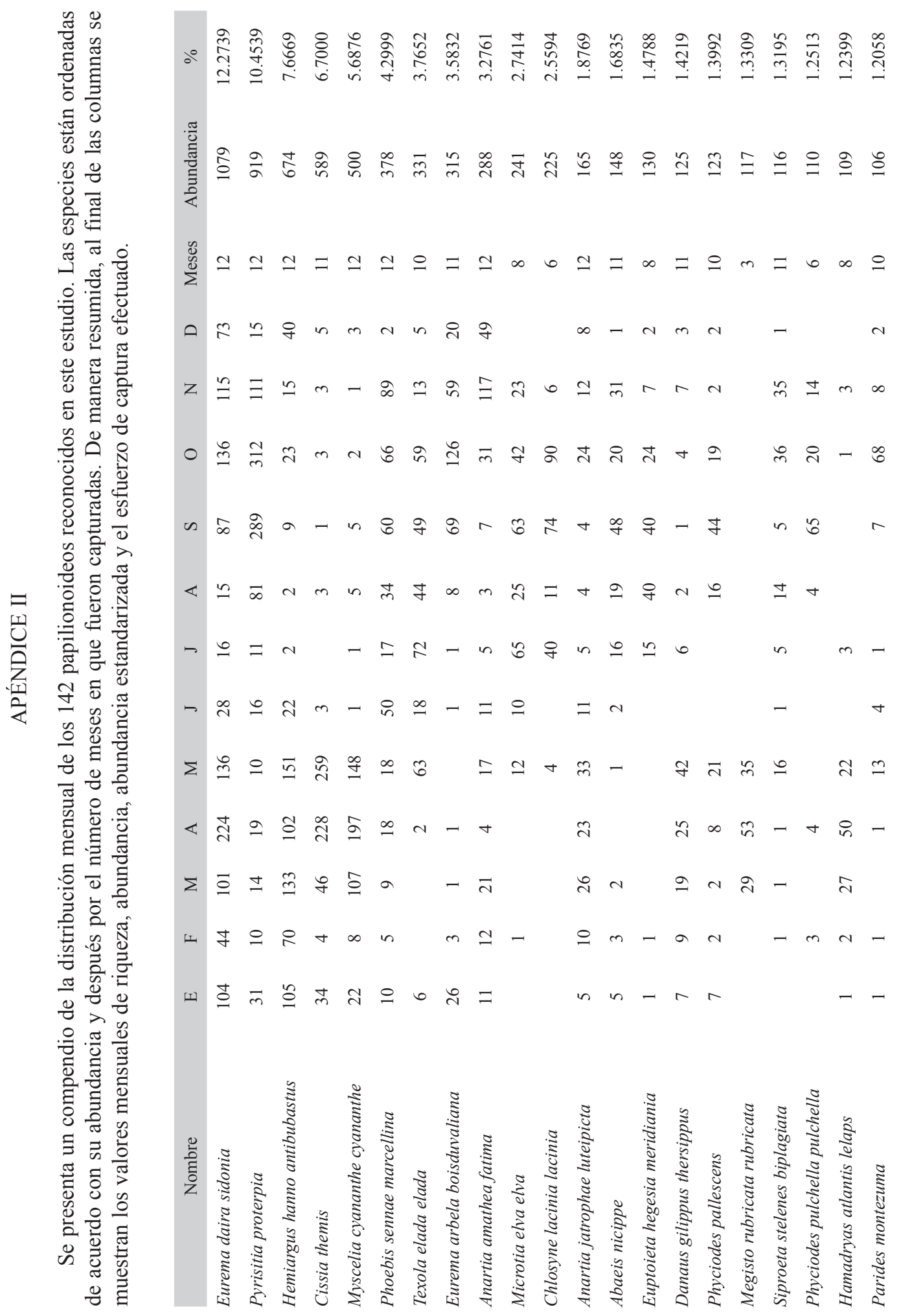




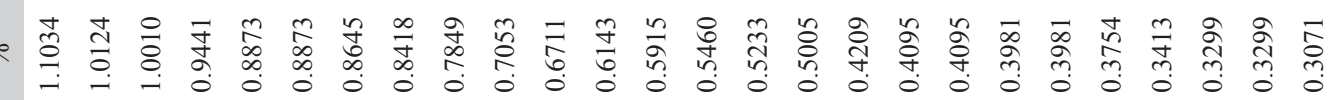

产节

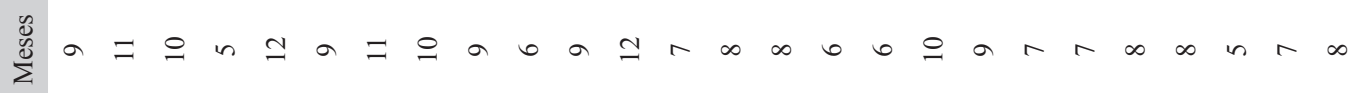

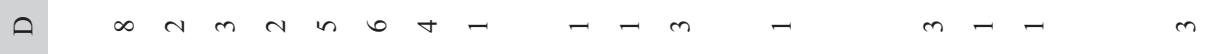

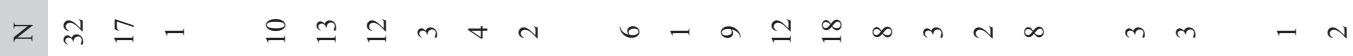

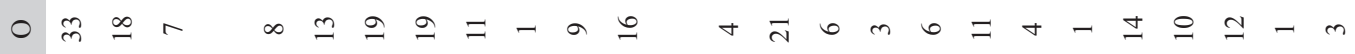

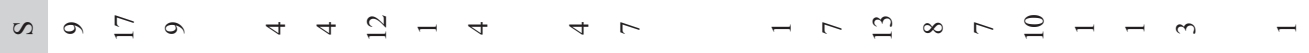

$\varangle+m-m+n-r+m-\infty m-$

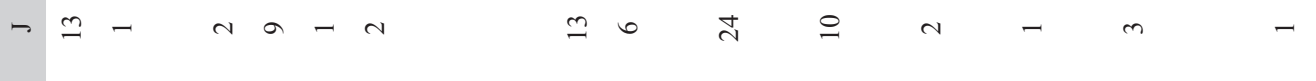

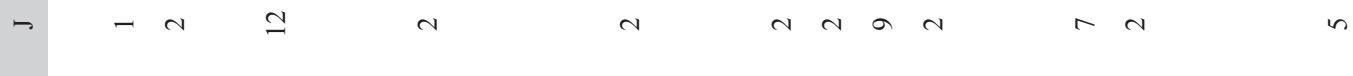

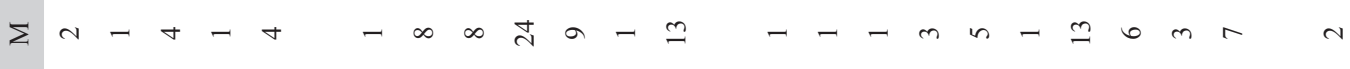

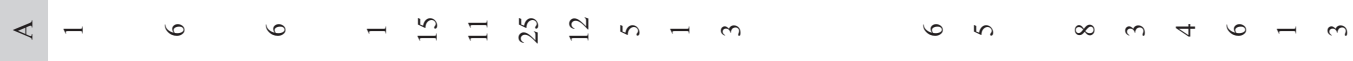

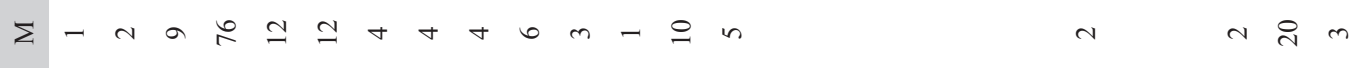

mi

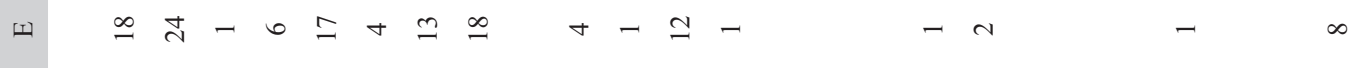

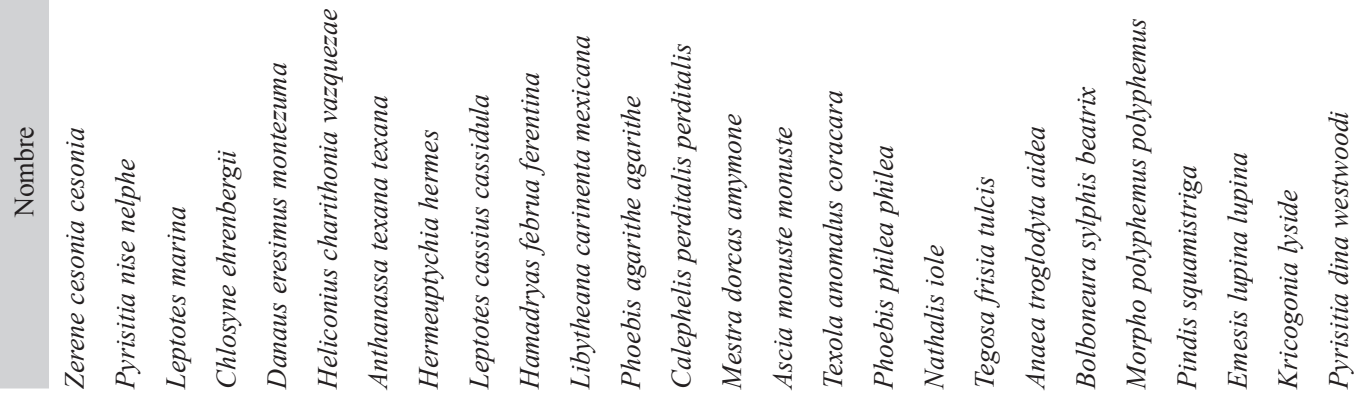




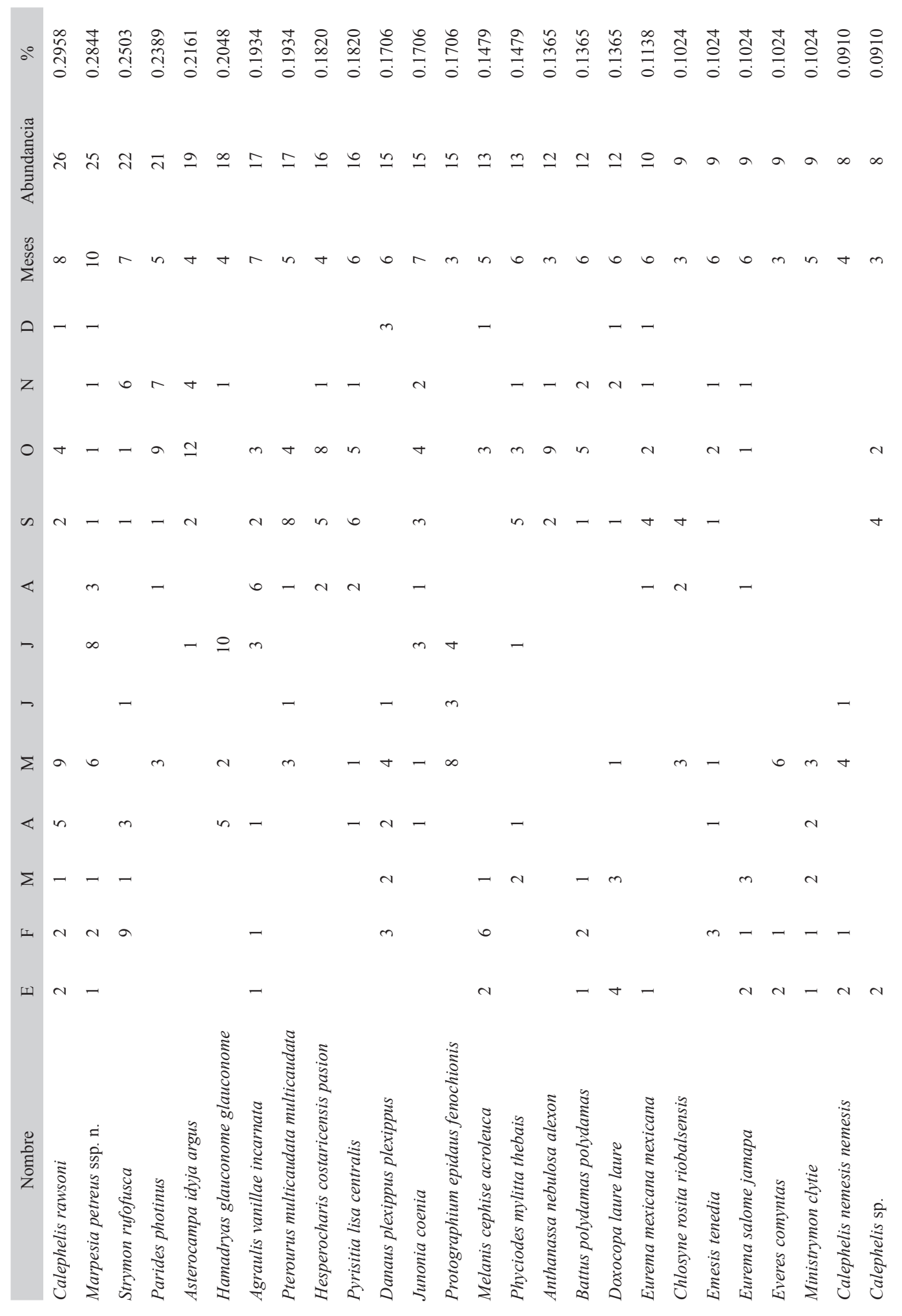




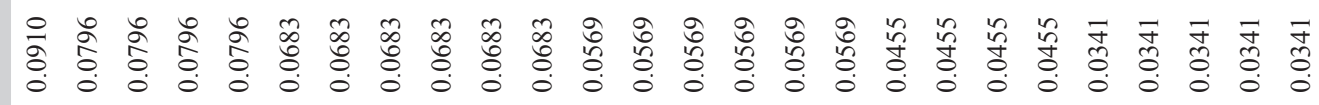

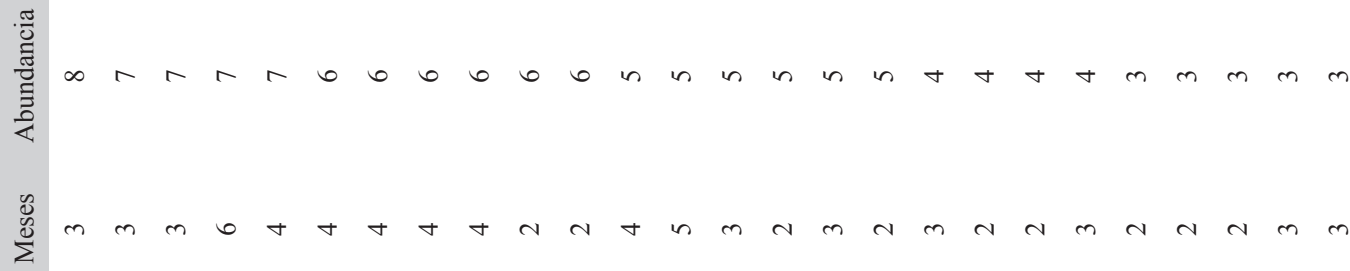

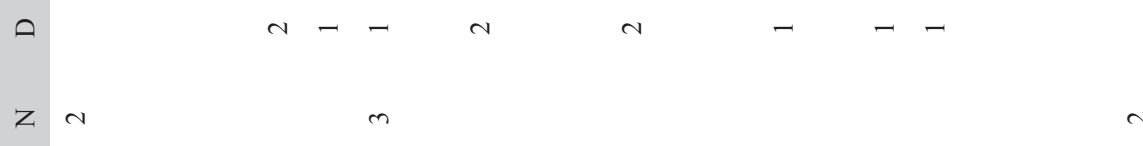
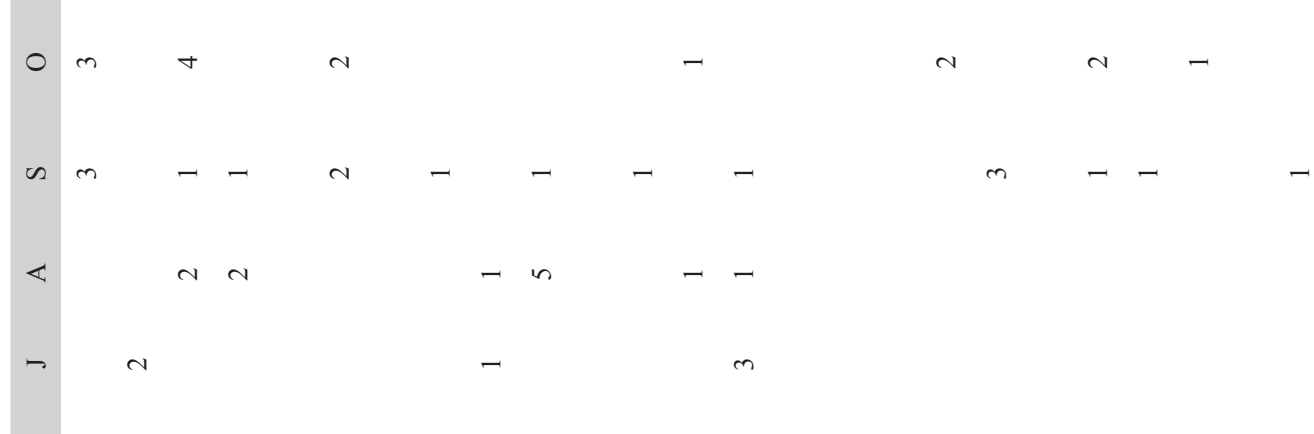

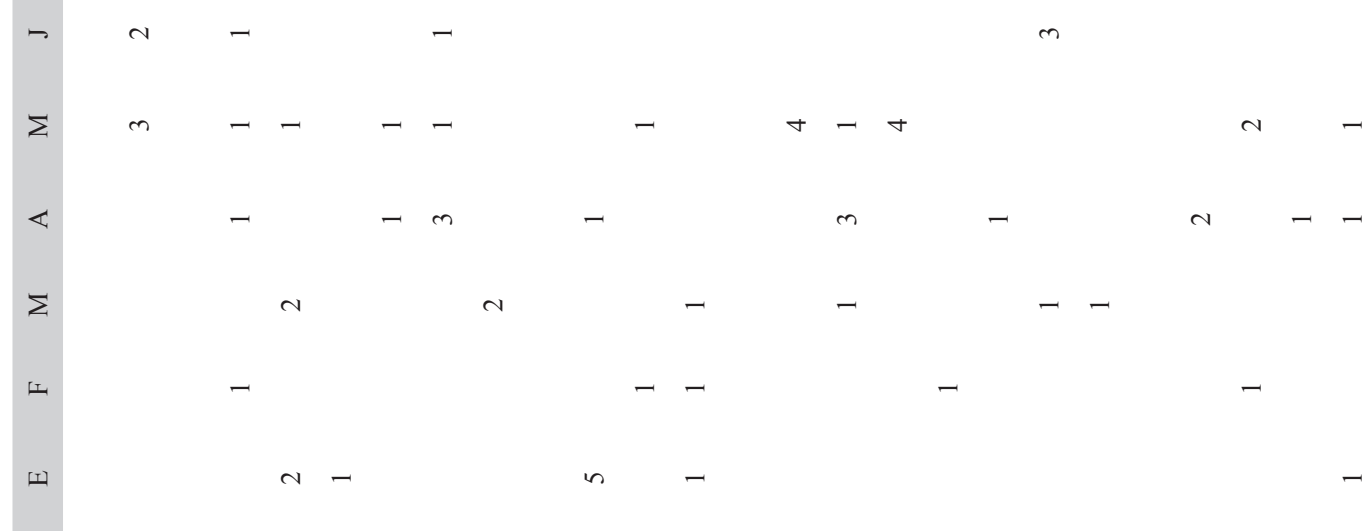

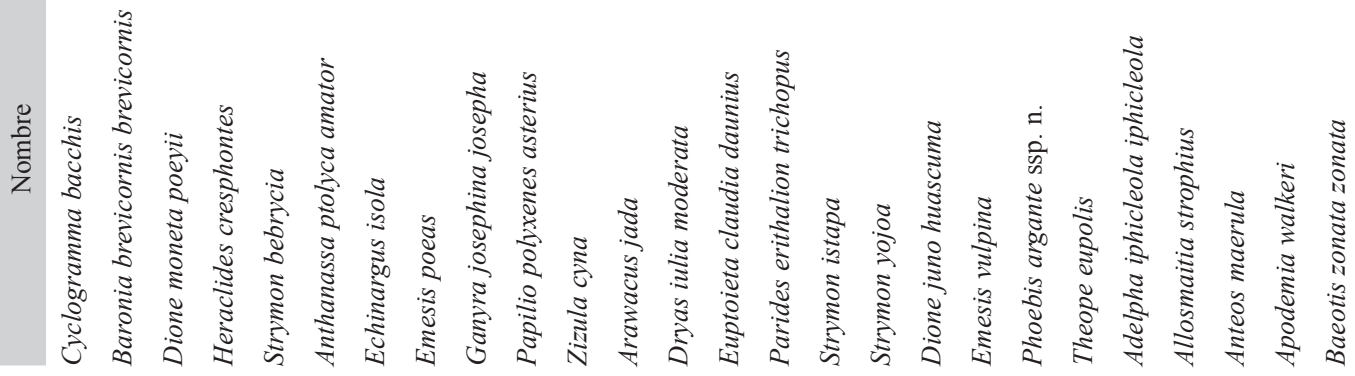




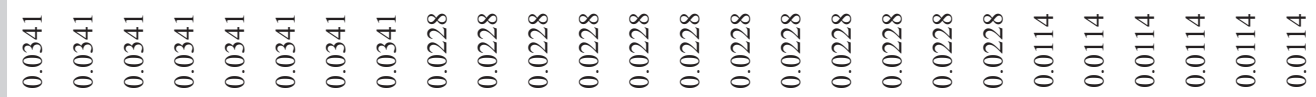

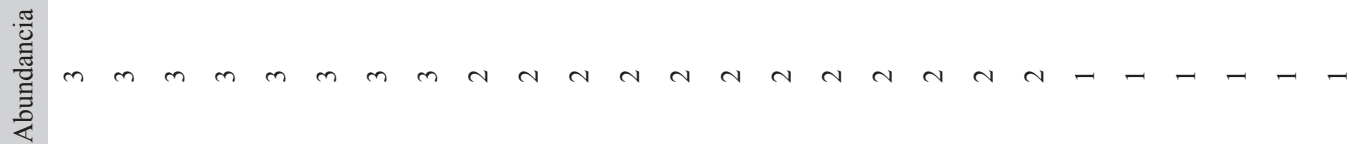

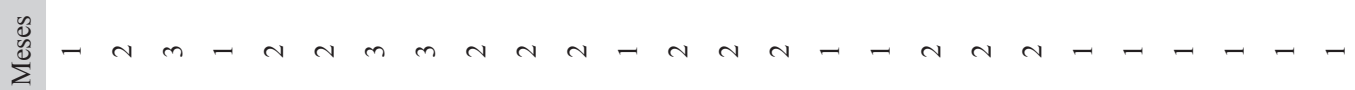

ค

z

N --

$\circ$

$\sim$

○

$m$

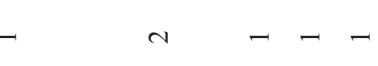

u

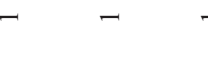

$\varangle$

$\mapsto$

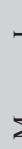

$\varangle \quad-$

$\Sigma \quad \sim-$

L

띠

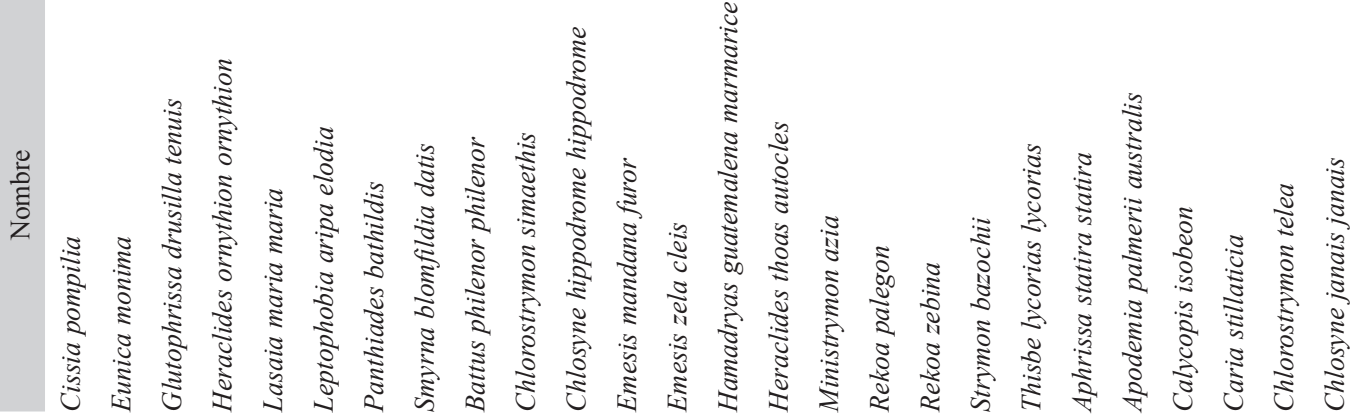




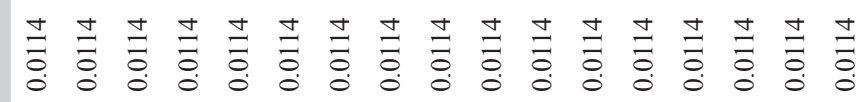

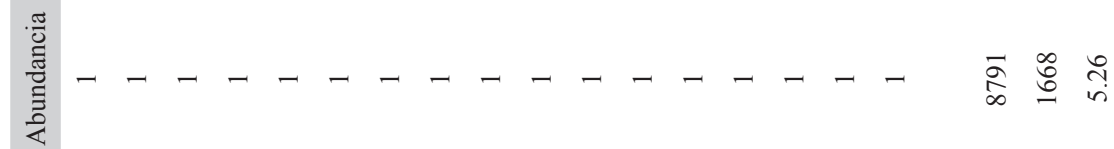

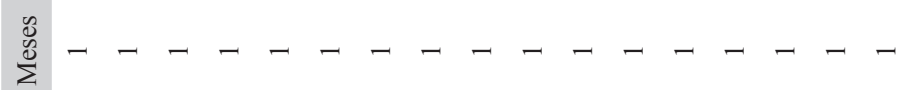

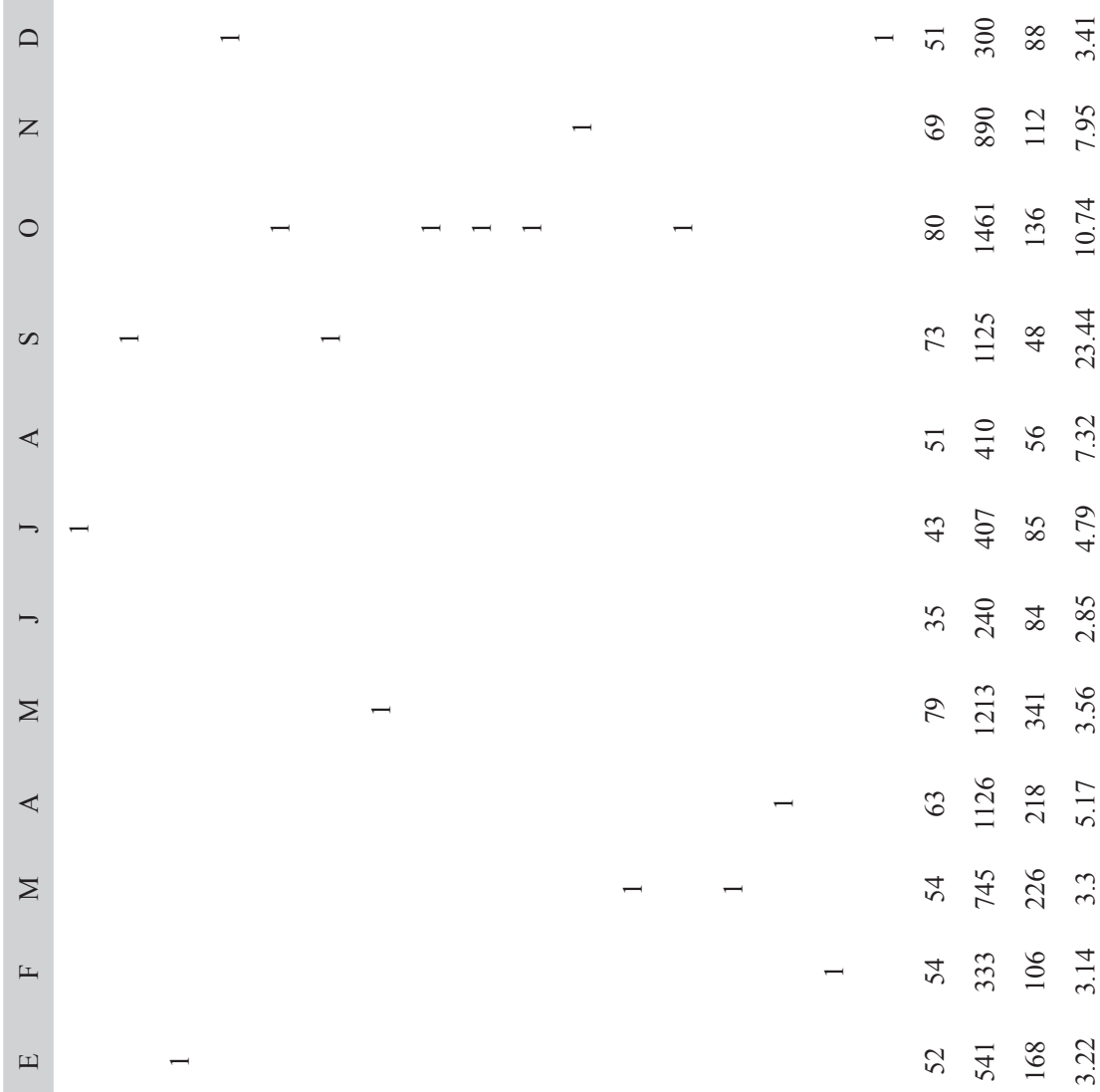

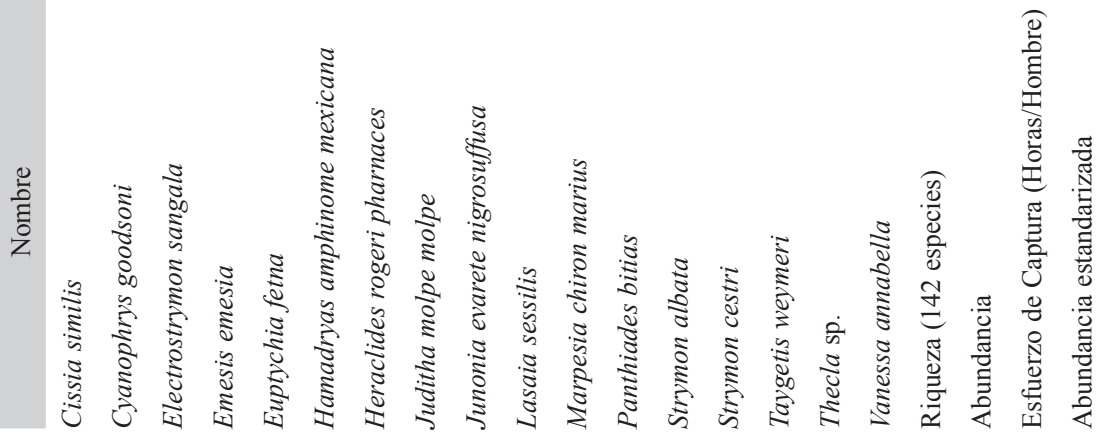

